Review

\title{
Advances in the Synthesis of Ring-Fused Benzimidazoles and Imidazobenzimidazoles
}

\author{
Martin Sweeney ${ }^{1}$, Darren Conboy ${ }^{2} \mathbb{D}$, Styliana I. Mirallai ${ }^{1} \mathbb{D}$ and Fawaz Aldabbagh ${ }^{1,2, * \mathbb{D}}$ \\ 1 School of Chemistry, National University of Ireland Galway, University Road, H91 TK33 Galway, Ireland; \\ M.Sweeney5@nuigalway.ie (M.S.); styliana.mirallai@nuigalway.ie (S.I.M.) \\ 2 Department of Pharmacy, School of Life Sciences, Pharmacy and Chemistry, Kingston University, Penrhyn \\ Road, Kingston upon Thames KT1 2EE, UK; D.Conboy@kingston.ac.uk \\ * Correspondence: F.Aldabbagh@kingston.ac.uk
}

check for updates

Citation: Sweeney, M.; Conboy, D.; Mirallai, S.I.; Aldabbagh, F. Advances in the Synthesis of Ring-Fused Benzimidazoles and Imidazobenzimidazoles. Molecules 2021, 26, 2684. https://doi.org/ $10.3390 /$ molecules26092684

Academic Editor: Farid Chemat

Received: 9 April 2021

Accepted: 3 May 2021

Published: 4 May 2021

Publisher's Note: MDPI stays neutral with regard to jurisdictional claims in published maps and institutional affiliations.

Copyright: (c) 2021 by the authors. Licensee MDPI, Basel, Switzerland. This article is an open access article distributed under the terms and conditions of the Creative Commons Attribution (CC BY) license (https:/ / creativecommons.org/licenses/by/ $4.0 /)$.

\begin{abstract}
This review article provides a perspective on the synthesis of alicyclic and heterocyclic ring-fused benzimidazoles, imidazo[4,5- $f$ ]benzimidazoles, and imidazo[5,4- $f$ ]benzimidazoles. These heterocycles have a plethora of biological activities with the iminoquinone and quinone derivatives displaying potent bioreductive antitumor activity. Synthesis is categorized according to the cyclization reaction and mechanisms are detailed. Nitrobenzene reduction, cyclization of aryl amidines, lactams and isothiocyanates are described. Protocols include condensation, cross-dehydrogenative coupling with transition metal catalysis, annulation onto benzimidazole, often using CuI-catalysis, and radical cyclization with homolytic aromatic substitution. Many oxidative transformations are under metal-free conditions, including using thermal, photochemical, and electrochemical methods. Syntheses of diazole analogues of mitomycin $C$ derivatives are described. Traditional oxidations of $o$-(cycloamino)anilines using peroxides in acid via the $t$-amino effect remain popular.
\end{abstract}

Keywords: green chemistry; halogen; heterocycle; hydrogen peroxide; imidazole; iodine; nitrosobenzene; oxone; palladium; quinone

\section{Introduction}

\subsection{Significance and Biological Activity}

Benzimidazole is an important heterocyclic pharmacophore. Therapeutic interest was aroused in the 1950s, when 5,6-dimethylbenzimidazole was discovered as a degradation product of vitamin- $B_{12}$ (Figure 1) [1,2]. Benzimidazoles possess a wide range of biological activities [3-6], significantly utilized as APIs in medicines [5], and as pesticides [6]. Moreover among the ring-fused benzimidazoles, pyrimido[1,2-a]benzimidazoles were discovered as effective corticotropin releasing factor-1 (CRF-1) receptor antagonists for potential treatment of mental health disorders [7]. A pyrrolo[1,2-a]benzimidazole was found to be the most effective cyclin-dependent kinase 4/6 (CDK4/6) inhibitor evaluated within a series of highly functionalized five to seven-membered alicyclic ring-fused benzimidazoles [8]. Other ring-fused benzimidazoles, the imidazobenzodiazepines were investigated as poly(ADP-ribose) polymerase (PARP-1) inhibitors, allowing reduction of hyperglycemia with neuroprotective effects in animal models [9].

The most widely studied of the applications of ring-fused benzimidazoles and imidazobenzimidazoles is as bioreductive antitumor agents, when the fused benzene part is an iminoquinone or quinone functionality (Figures 2-5). Indole-based natural products often inspire analogue synthesis, including imidazoquinoxalinone analogues of the marine natural product, wakayin [10], a topoisomerase I inhibitor (Figure 2). 

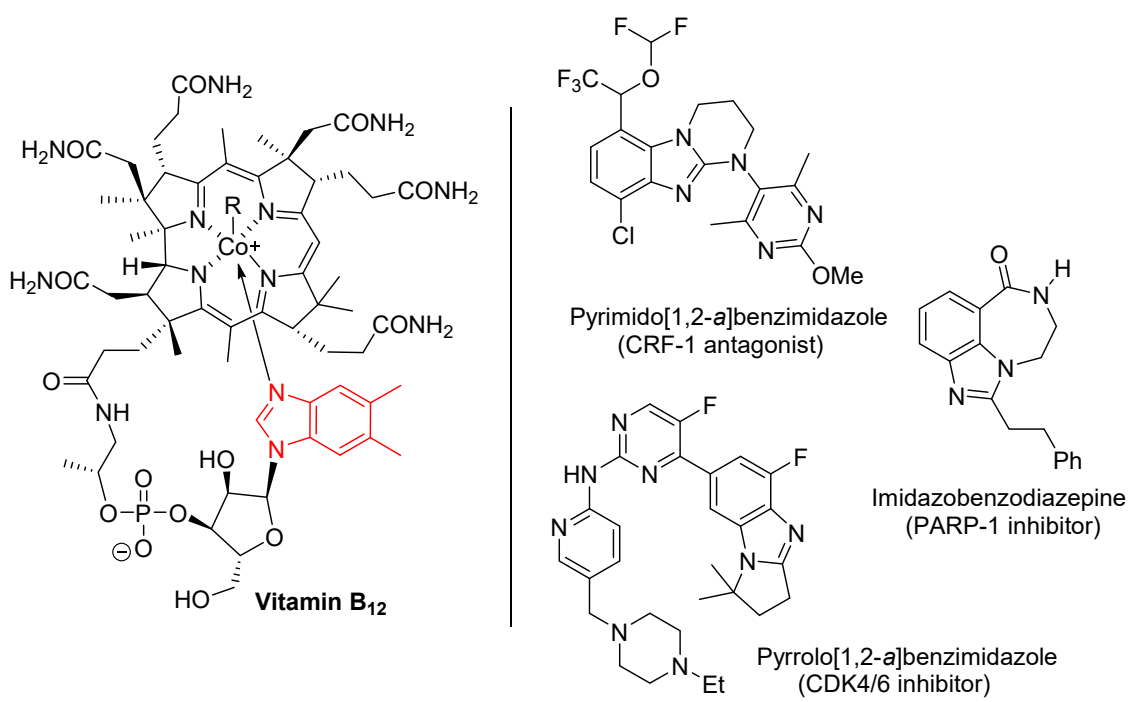

Figure 1. Benzimidazole in vitamin $B_{12}$ and biologically-active ring-fused systems [1-9].
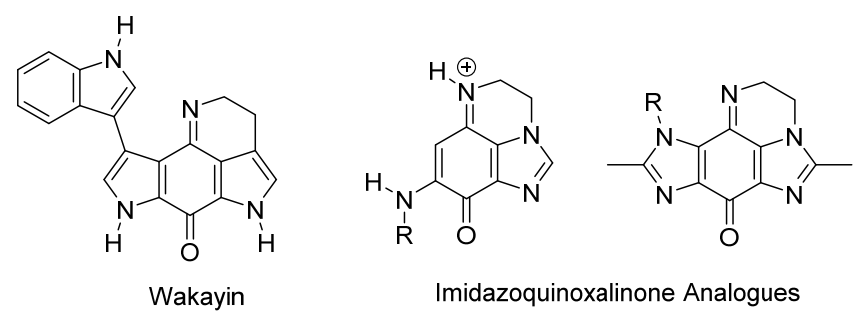

Figure 2. Imidazole-based wakayin analogues [10].

Mitomycin C (MMC) has, however, attracted most interest, as the archetypal bioreductive antitumor antibiotic, which cross-links to DNA [11]. Incorporation of the DNAalkylating aziridinyl moiety leads to cytotoxicity via the FANC DNA-repair pathway [12,13], and the benzimidazole analogue of the bioactivated form of MMC (aziridinomitosene) was prepared and evaluated against breast cancer cell lines [14] (Figure 3). Skibo has published extensively on aziridinylpyrrolo[1,2-a]benzimidazolequinones (PBIs) as DNA cleaving agents with analogues showing melanoma-specific cytotoxicity [15-18].<smiles>CC(=O)OCC1C2=C(C(=O)C(C)=C(N3CC3)C2=O)N2CC3NC1C32C</smiles><smiles>O=C1C(N2CC2)=CC(=O)c2c1nc1n2CCC1</smiles>

Cytotoxicity via the FANC-Pathway<smiles></smiles><smiles>c1ccc2c(c1)nc1n2CC2[N-]C12</smiles>

Benzimidazole Analogue

Figure 3. Aziridinyl-functionalized antitumor agents [11-18].

One or two-electron reductases are responsible for bioreductive activation. NADPHcytochrome $c(\mathrm{P} 450)$ reductase is predominant under hypoxic conditions with the oneelectron reduction reversed by oxygen [19]. Many solid tumors also over-express the obligatory two-electron reductase $\mathrm{NAD}(\mathrm{P}) \mathrm{H}$ :quinone oxidoreductase 1 (NQO1, also known as DT-diaphorase), which is a popular target for anti-cancer studies [20]. Many anti-cancer 
agents do not contain conventional DNA damaging functionality, and cytotoxicity may be due to the formation of reactive oxygen species. Pyrido[1,2-a]benzimidazolequinone 1 (Figure 4) is more than 300 times more cytotoxic under hypoxic conditions than the clinical drug, MMC (Figure 3), with cytotoxicity for alicyclic ring-fused benzimidazoles correlated to reductive potentials [21,22]. Highly conjugated naphthyl fused benzimidazolequinone 2 leads to increased stability of reduced intermediates leading to specificity towards human cancer cell lines over-expressing NQO1 [23].
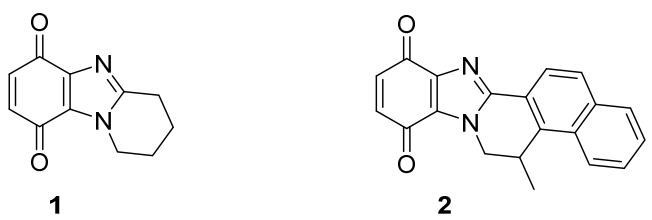

Figure 4. Benzimidazolequinones targeting over-expressed reductases in solid tumors [21-23].

Ring-fused imidazo[4,5-f]benzimidazolequinones $\mathbf{3 a}$ and $\mathbf{3 b}$ are NQO1 substrates [24,25], with 3a, at the National Cancer Institute (NCI), showing specificity towards the killing of melanoma cell lines (Figure 5) [24]. Our group was the first to provide viable synthetic protocols for accessing ring-fused imidazo[5,4- $f$ ]benzimidazoles, enabling evaluation of quinone and iminoquinone derivatives for toxicity against cancer cell lines [26-29]. Compared to alicyclic ring-fused analogues $4 \mathbf{a}$ and $\mathbf{4 b}$, the oxygen atom of the 1,4-oxazino ring was found to increase toxicity of $4 \mathbf{c}$ [27]. Iminoquinone 5a isolated from the Fremy oxidation to prepare $4 \mathrm{~b}$, was unexpectedly the most potent imidazobenzimidazole, with more than 12 times greater cytotoxicity towards a prostate cancer cell line (DU145) than a normal fibroblast cell line (GM00637) [26]. More intensive cytotoxicity assays, computational docking, and NCI COMPARE analysis on 5a, revealed good correlation with NQO1 [28]. In contrast, isomeric imidazo[4,5-f] benzimidazole $5 \mathbf{b}$ was inactive against the NCI 60 cell line panel [29].

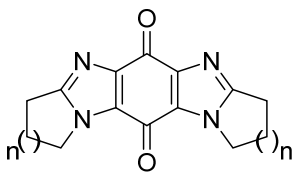

3a: $\mathrm{n}=1$ 3b: $n=2$<smiles>[X]C1CCn2c1nc1c(C)c3nc4nc-3nc(c1c2=O)C4</smiles>

4a: $\mathrm{n}=1, \mathrm{X}=\mathrm{CH}_{2}$ 4b: $\mathbf{n}=2, \mathrm{X}=\mathrm{CH}_{2}$ 4c: $n=2, X=0$

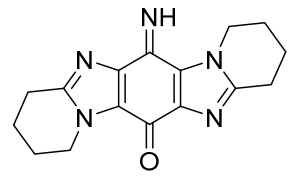

$5 a$

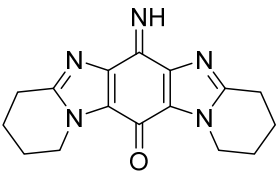

5b

Figure 5. Imidazobenzimidazolequinones and iminoquinones [24-29].

\subsection{Available Synthetic Methods}

The categories of syntheses of ring-fused benzimidazoles 6 are according to the cyclization reaction (Scheme 1). Oxidative cyclizations from aniline or anilide derivatives is the most studied route (Route A) and is presented in context with the plethora of other syntheses that build the benzimidazole moiety (Routes B-D). The section on Route A is sub-divided into syntheses of benzimidazole and imidazobenzimidazole scaffolds. Lastly, there is a section on syntheses, which begin with the benzimidazole moiety (Route E), sub-divided according to reaction (type) conditions. This is not an exhaustive review, and the reader should consult reviews on polycyclic benzimidazoles for comprehensive lists of syntheses [30-33]. Since the late 1990s, Aldabbagh et al. have worked on the discovery of new ring-fused benzimidazoles and synthetic methods, and the collated articles related to their research are reviewed herein. A reviewer recommended a Scifinder ${ }^{n}$ search of "benzimidazole-fused", which was completed, and significant references are incorporated. For brevity, full papers are cited and not the preceding communication article. A historical perceptive is taken and analysis of the most significant contributions to the field is carried 
out. In particular, methodology that forms a variety of ring-fused benzimidazoles is of interest, rather than procedures that give mainly the benzimidazole core.

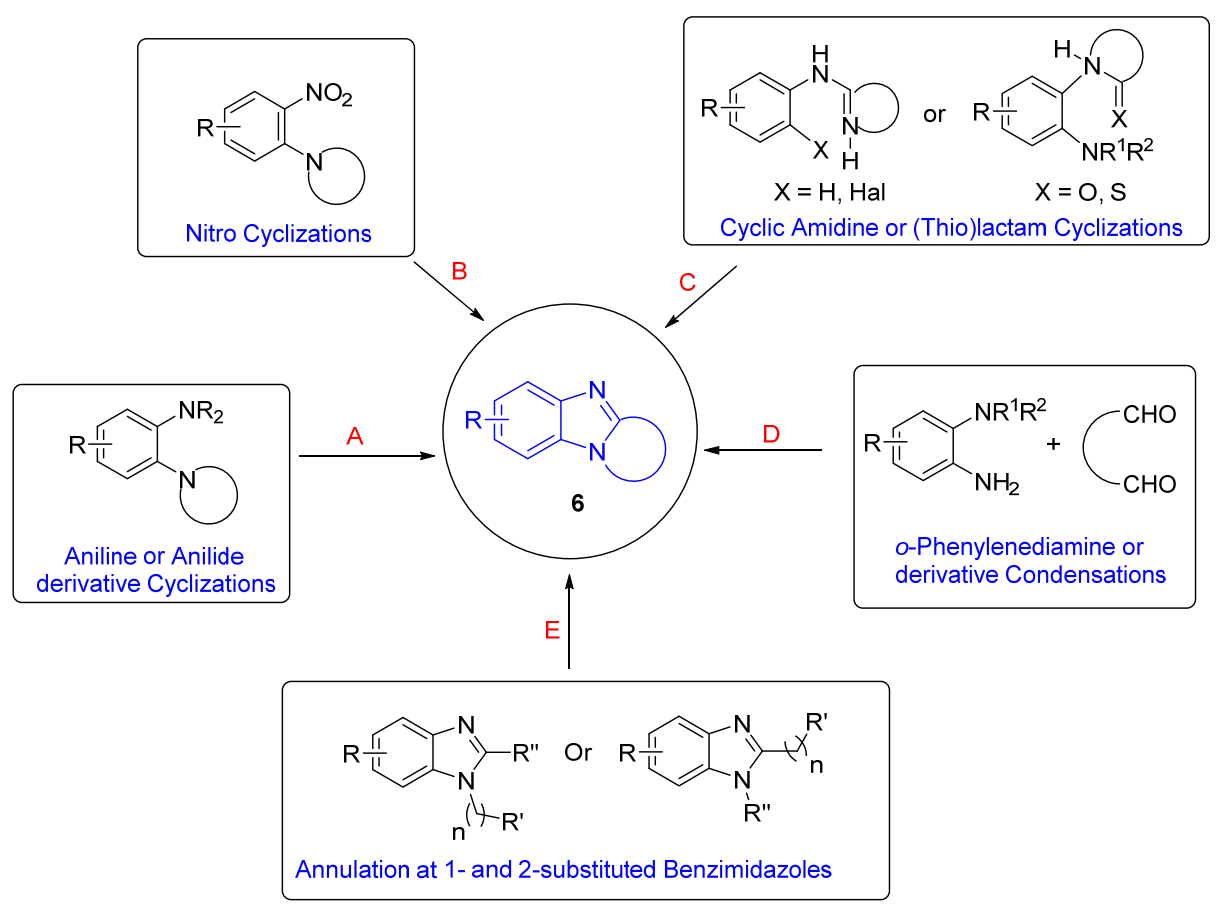

Scheme 1. Categorizing available synthetic methods according to the cyclization reaction A-E.

\section{Syntheses of Ring-Fused Benzimidazoles and Imidazobenzimidazoles}

\subsection{Oxidations of o-Cycloaminoanilines and Anilide Derivatives (Route A)}

There are distinct differences in the reaction mechanisms and conditions for ring-fused benzimidazole and imidazobenzimidazole formation warranting sub-division. Benzimidazoles form by oxidative cyclization of anilines via nitrosobenzene intermediates; in contrast, cyclization to give the ring-fused imidazobenzimidazole must begin from anilides and proceed via amine $\mathrm{N}$-oxide intermediates under acidic conditions.

\subsubsection{Forming Ring-Fused Benzimidazoles}

In 1908, Spiegel and Kaufmann reported that Caro's acid (peroxymonosulfuric acid, $\mathrm{H}_{2} \mathrm{SO}_{5}$ ) oxidized 5-nitro-2-(piperidin-1-yl)aniline to 7-nitro-1,2,3,4-tetrahydropyrido[1,2a]benzimidazole [34]. In the absence of the nitro-substituent, no oxidative cyclization occurred. Caro's acid was already known to oxidize anilines to nitrosobenzenes [35], so supporting the idea of a nitroso intermediate. The prominent 20th century chemist and creator of Adam's catalyst, Roger Adams with Nair refined this methodology, and accessed a range of five to seven-membered ring-fused benzimidazoles in good to high yields using peroxytrifluoroacetic acid generated in situ from $\mathrm{H}_{2} \mathrm{O}_{2}$ and trifluoroacetic acid (TFA) (Scheme 2) [36]. Six-membered cyclization yields were higher, when the anilines contained a nitro-substituent. Meth-Cohn and Suschitzky [37] soon refuted the observation made by Nair and Adams that acyl derivatives do not undergo cyclization to give benzimidazoles. These workers showed a range of anilide derivatives (formyl, acetyl and benzoyl) underwent oxidative cyclizations using peroxytrifluoroacetic acid or performic acid $\left(\mathrm{H}_{2} \mathrm{O}_{2}\right.$ and $\mathrm{HCO}_{2} \mathrm{H}$ ). Meth-Cohn preferred the use of $o$-cyclic amine substituted anilides as substrates for making ring-fused benzimidazoles [37,38]. Meth-Cohn commented that Nair and Adams [36] had possibly formed the anilide in situ, due to the initial addition of TFA followed by $\mathrm{H}_{2} \mathrm{O}_{2}$ [38]. Mechanisms were proposed for benzimidazole formation from anilide, via an amine- $\mathrm{N}$-oxide rather than the nitroso intermediate (see Section 2.1.2). Later 
the use of anilide derivatives as substrates for preparation of ring-fused benzimidazoles would become commonplace (Scheme 3) [13,15,27,37-40].

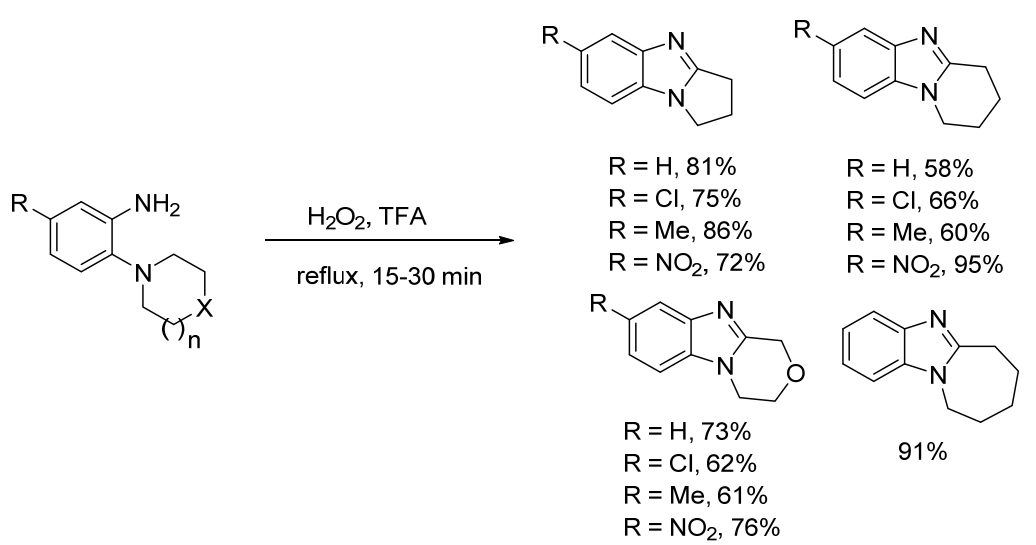

Scheme 2. Nair and Adams oxidative cyclizations of anilines [36].

Significant amounts of seven- and eight-membered ring-fused [1,2-a]benzimidazoles $9 a$ and $9 b$ were formed from nitrobenzenes $7 a$ and $7 b$ during the one-pot catalytic hydrogenation and acetylation to give acetamides $\mathbf{8 a}$ and $\mathbf{8 b}$ (Scheme 3a) [39]. It seemed that the conformation of these large alicyclic rings favored advantageous cyclization of nitroso intermediates formed during the hydrogenation process. Acetamides $\mathbf{8 a}$ and $\mathbf{8 b}$ were cyclized using performic acid to $\mathbf{9 a}$ and $\mathbf{9 b}$ in good yields, with the former transformed to 3-aziridinylazepino[1,2-a]benzimidazolequinone [13,39]. A readily available and safer alternative to Caro's acid is Oxone $\left(2 \mathrm{KHSO}_{5} \cdot \mathrm{KHSO}_{4} \cdot \mathrm{K}_{2} \mathrm{SO}_{4}\right)$ [41]. Due to the absence of organic waste products, Oxone in the presence of formic acid gives ring-fused benzimidazole [27,40] and imidazobenzimidazole [27] adducts without the requirement for chromatography. 2-Oxa-7-azaspiro[3.5]nonane acetamide $\mathbf{1 0}$ gave the spirocyclic oxetane ring-fused benzimidazole $\mathbf{1 1}$ in good yield by simple organic extraction from the basified aqueous mixture (Scheme 3b) [40].

(a)

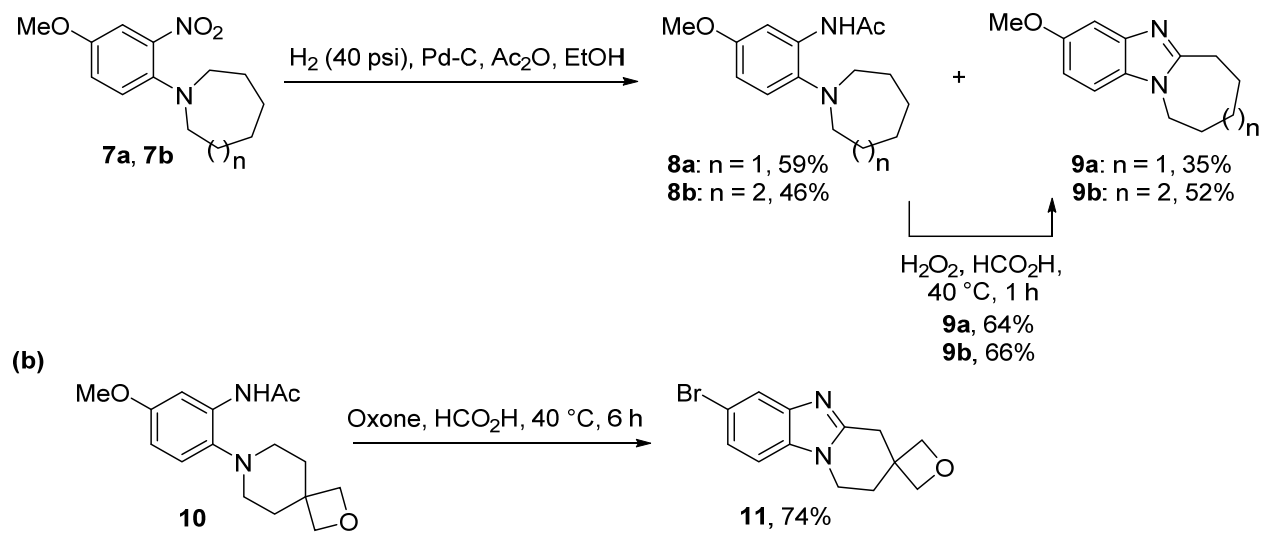

Scheme 3. Acetanilide cyclizations onto (a) azepino- and azocino- [39], and (b) spirocyclic oxetane[40] derivatives.

Preparations of ring-fused benzimidazoles using o-cyclic amine substituted anilines with performic acid compare favorably with the derivative anilide reaction, with Smalley et al. reporting moderate to good yields for five- to seven-membered adducts (Scheme 4a) [42]. In a more recent study, recyclable ethyl acetate (EtOAc) replaced formic acid, with aqueous effluent, organic-aqueous extraction and chromatography avoided for the preparation of pyrrolo[1,2-a]benzimidazoles from commercial o-(pyrrolidin-1-yl)anilines (Scheme 4b) [43]. 
Although, the presence of strong electron-withdrawing substituents $\left(\mathrm{NO}_{2}, \mathrm{CN}\right)$ and the six-membered cyclization required methanesulfonic acid $(\mathrm{MsOH})$ to reach high yields. However, $\mathrm{MsOH}$ is a green acid undergoing biodegradation by forming $\mathrm{CO}_{2}$ and sulfate [44].

(a)

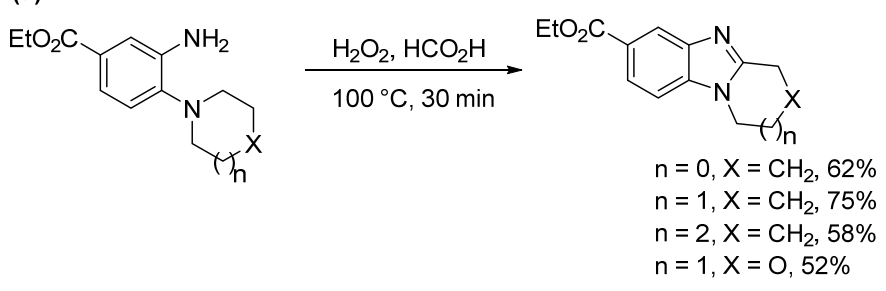

(b)

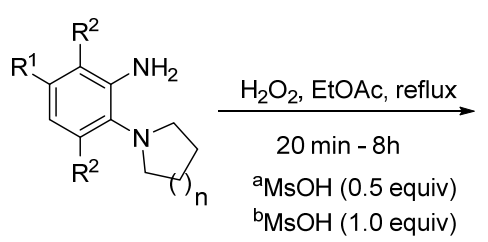<smiles>[R]c1ccc2c(c1)nc1n2CCC1(C)C</smiles>

$\mathrm{R}^{1}=\mathrm{H}, \mathrm{Me}, \mathrm{OMe}, \mathrm{NHAc}$, $\mathrm{Br}, \mathrm{F}, \mathrm{CN}^{\mathrm{a}} \mathrm{CF}_{3}, \mathrm{NO}_{2}{ }^{\mathrm{a}}$<smiles>COc1ccc(OC)c2c1nc1n2CCCCCC1</smiles><smiles>COc1ccc(OC)c2c1nc1n2CCC1</smiles>

\section{$\mathrm{OMe}$}<smiles>COc1cccc2nc3n(c12)CCCC3</smiles>
$75 \%^{\mathrm{b}}$<smiles>COc1ccc(OC)c2c1nc1n2CCCCC1</smiles>

$65 \%$

Scheme 4. Aniline cyclizations using (a) performic acid [42] and (b) acid-free conditions [43].

Alternatives to peroxide-based oxidizing systems, include $\mathrm{MnO}_{2}$ in cold chloroform, but yields of ring-fused benzimidazoles from $o$-cycloaminoanilines were $15-20 \%$ due to presumed formation of azo-compounds [45]. Möhrle and Gerloff reported the use of a $\mathrm{Hg}$ (II) EDTA complex to deliver ring-fused benzimidazoles, in quantitative yield, apart from the morpholino compound, synthesized in $47 \%$ yield (Scheme 5) [46].

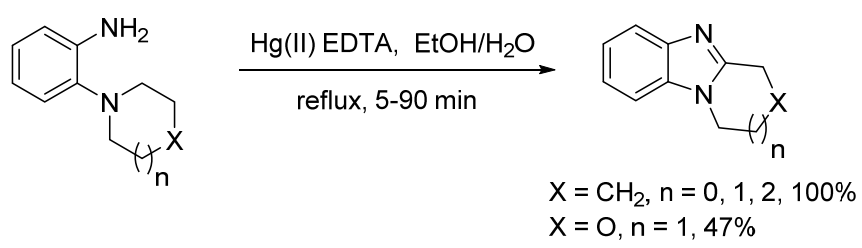

Scheme 5. $\mathrm{Hg}(\mathrm{II})$-mediated oxidative synthesis [46].

The cross dehydrogenative coupling (CDC) involves forming the $\mathrm{C}-\mathrm{N}$ bond directly from C-H and $\mathrm{N}-\mathrm{H}$ bonds under oxidative conditions with a formal loss of $\mathrm{H}_{2}$, in a process often catalyzed by transition metals. CDC is used to describe pentamethylcyclopentadienyl $\operatorname{Ir}(\mathrm{III})$ dichloride $\left(\left[\mathrm{Cp}^{*} \mathrm{IrCl}_{2}\right]_{2}\right.$ ) catalyzed oxidative cyclization of $o$-tetrahydroisoquinoline substituted aniline derivatives (Scheme 6a) [47]. The bulk around the primary amine dictated regioselectivity. The $o$-cyclic amine substituted aniline gave the benzimidazo[2,1a] isoquinoline 12, while the more hindered acetamide derivative gave the alternative kinetic product 13 . The formamide has less steric bulk than the acetamide forming a mixture of the thermodynamic and kinetic products. The reaction was extended to the synthesis of pyrrolo-, pyrido-, and azepino-[1,2-a]benzimidazoles, without the requirement for a ligand (Scheme 6b), but was less successful for making morpholino- and piperazino-ring-fused analogues [48]. 
(a)

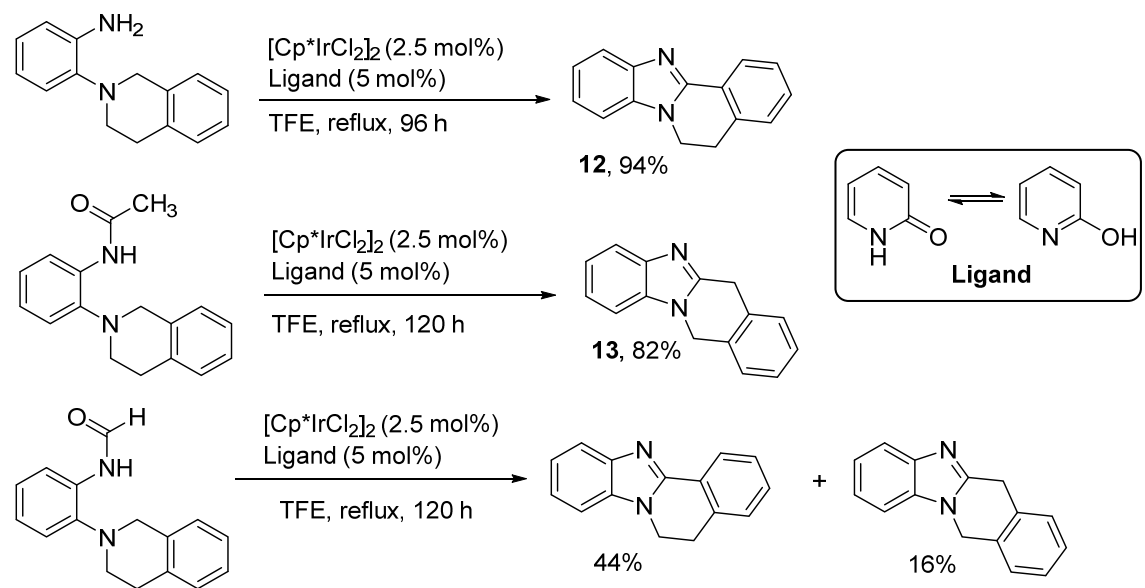

(b)

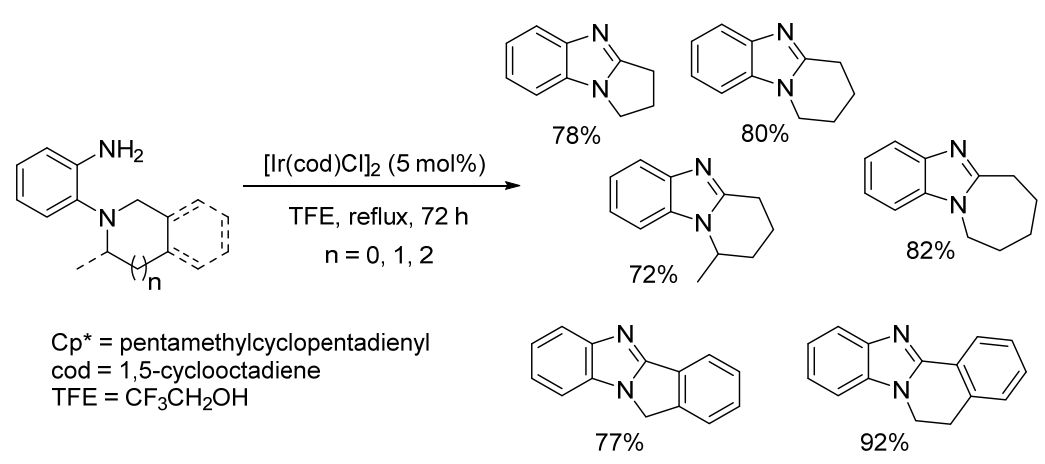

Scheme 6. Ir(III)-mediated cyclizations (a) with ligand [47] and (b) without ligand [48].

The isoindoline and tetrahydroisoquinoline substrates are the easiest to oxidize at high temperatures, including in the presence of TEMPO in air (Scheme 7a) [49], and catalytic iron(III) [50]. The latter gave the highest yields for the benzimidazo[2,1- $a$ ]isoquinoline systems (Scheme 7b).

(a)
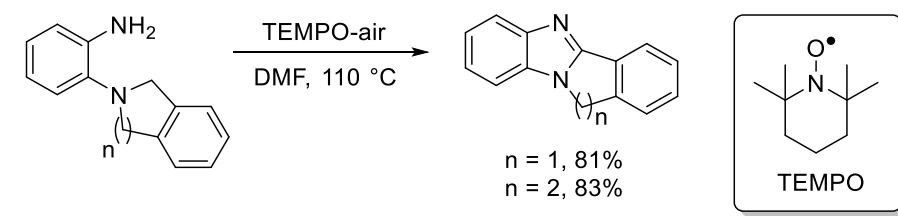

(b)<smiles>Nc1cc[R1]cc1N1CC[R1]c2ccccc2C1</smiles>

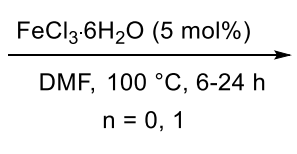<smiles>[R17]c1ccc2nc3n(c2c1)CCc1ccccc1-3</smiles><smiles>c1ccc2c(c1)nc1n2CCC1</smiles>

Scheme 7. Thermal oxidative cyclizations mediated by (a) TEMPO/air [49] and (b) Fe(III) [50].

Aniodic oxidation gave the required iminium ion 14 for cyclization (Scheme 8) [51]. The electrolyte was $n-\mathrm{Bu}_{4} \mathrm{NPF}_{6}(20 \mathrm{~mol} \%)$, and the anode is reticulated vitreous carbon (RVC), and $\mathrm{Pt}$ is the cathode in an undivided cell at a constant current of $10 \mathrm{~mA}$. A Russian team reported the electrochemical oxidative cyclization with reduction of nitrobenzene for cyclization onto an $o$-piperidinyl-substituent to give pyrido[1,2-a]benzimidazoles [52]. 


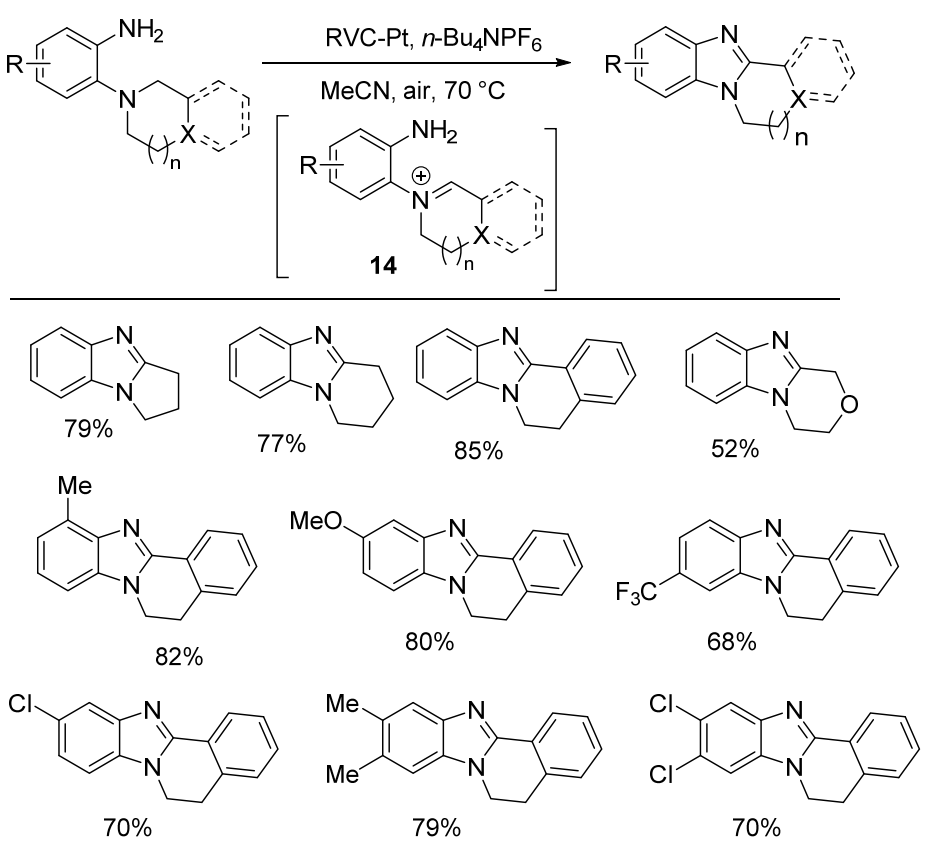

Scheme 8. Electrochemical oxidative cyclizations [51].

In the early 1970s, o-cyclic amine substituted anilines reacted in neat sulfuryl chloride in an oxidative cyclization with concomitant tetrachlorination of the activated aromatic nucleus (Scheme 9) [53]. The attempt to tetrachlorinate the $o$-pyrrolo substituted aniline analogue led to an inseparable mixture of mono-, di-, and trichloro ring-fused benzimidazoles.
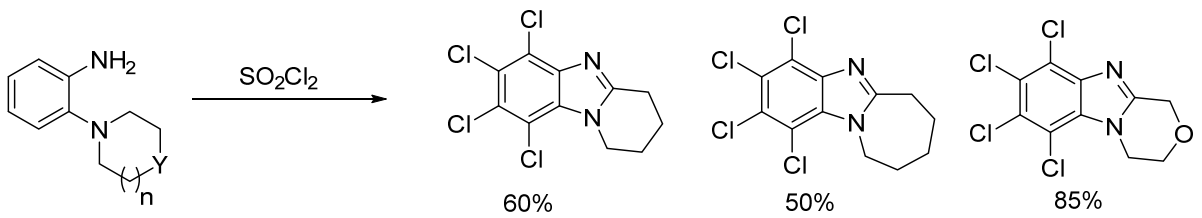

Scheme 9. Synthesis of polychlorinated ring-fused benzimidazoles using $\mathrm{SO}_{2} \mathrm{Cl}_{2}$ [53].

More recently, we heralded the use of $\mathrm{H}_{2} \mathrm{O}_{2}$ with hydrohalic acid (HX), as a convenient oxidizing and halogenation system for organic synthesis [54-56]. The system allows in situ generation of $\mathrm{Cl}_{2}$ and $\mathrm{Br}_{2}$, with the only by-product, being water (Scheme 10). The salt of hypochlorous acid $(\mathrm{HOCl})$ is the active ingredient in domestic bleach and is the intermediate of the reaction between $\mathrm{H}_{2} \mathrm{O}_{2}$ and $\mathrm{HCl}$.

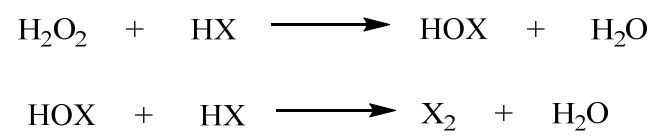

Scheme 10. Molecular halogen $\left(\mathrm{X}_{2}\right)$ generated from $\mathrm{H}_{2} \mathrm{O}_{2}$ and $\mathrm{HX}$ [54-56].

Domestic bleach gave cyclization and dichlorination of aniline 15 in $56 \%$ yield (Scheme 11a), with the lower yield attributed to the requirement for chromatography to separate the additives in the bleach [54]. Moreover, using $\mathrm{H}_{2} \mathrm{O}_{2} / \mathrm{HX}$ a library of selectively dichlorinated and dibrominated ring-fused benzimidazoles was prepared in high yields from commercial $o$-cyclic amine substituted anilines, with most cases not requiring chromatography (Scheme 11b,c). 5-Fluoro-2-piperidinylaniline was an exception, giving significant amounts of cyclization with monochlorination or monobromination. Bromination tended to be slower than chlorination, and tribrominated product $\mathbf{1 6}$ was isolated for the $o$-(pyrrolidin- 
1-yl)aniline, due to difficulties in cleanly isolating 5,7-dibromopyrrolo[1,2-a]benzimidazole (Scheme 11d).

(a)<smiles>Nc1cc(Br)ccc1N1CCCCC1</smiles>

15 (i) Domestic bleach, $\mathrm{HCl}, \mathrm{MeCN}$, reflux, $1 \mathrm{~h}$

$\mathrm{OR}$ (ii) $\mathrm{H}_{2} \mathrm{O}_{2}$ (10 equiv), $\mathrm{HCl}$ (12 equiv), MeCN, reflux, $20 \mathrm{~min}$<smiles>Clc1cc2c(nc3n2CCCC3)c(Cl)c1Br</smiles>

using (i) $56 \%$ using (ii) $90 \%$

(b)

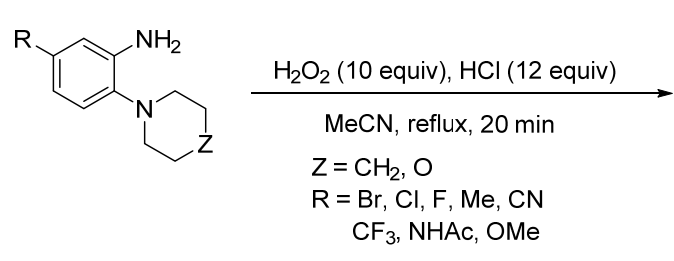<smiles></smiles><smiles>O=[N+]([O-])c1cc2c(cc1Cl)nc1n2CCCC1</smiles>

$27 \%$

(c)<smiles>[R]c1ccc(N2CCCCC2)c(N)c1</smiles>

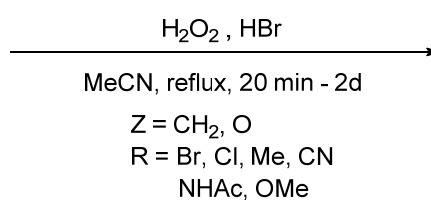<smiles>[R]c1c(Br)cc2c(nc3n2CC[Z]C3)c1Br</smiles>

$62-94 \%$<smiles>Fc1c(Br)cc2c(nc3n2CCCC3)c1Br</smiles><smiles>Fc1cc2nc3n(c2cc1Br)CCCC3</smiles>

$31 \%$

(d)

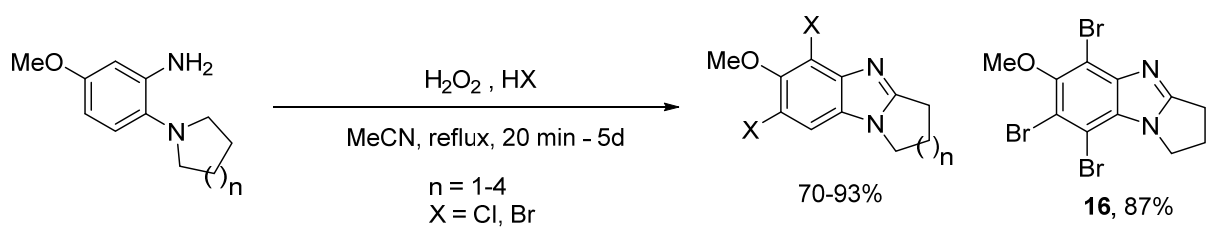

Scheme 11. One-pot ring closure with selective halogenation using (a) domestic bleach or $\mathrm{H}_{2} \mathrm{O}_{2} / \mathrm{HCl}_{\text {, }}(\mathbf{b}) \mathrm{H}_{2} \mathrm{O}_{2} / \mathrm{HCl}_{\text {, and }}$ (c) $\mathrm{H}_{2} \mathrm{O}_{2} / \mathrm{HBr}$, and (d) five to eight-membered ring-fused adducts [54].

3,6-Dimethoxy-2-(cycloamino)anilines underwent 6-electron oxidations to afford a variety of ring-fused halogenated benzimidazolequinones, when using higher amounts of $\mathrm{HCl}$ or $\mathrm{HBr}$ relative to $\mathrm{H}_{2} \mathrm{O}_{2}$ (Scheme 12a) [55]. The active species is the elemental halogen $\left(\mathrm{X}_{2}\right)$ with water required for quinone formation (Scheme 12b). When less in situ halogen was generated, using $\left[\mathrm{H}_{2} \mathrm{O}_{2}\right]>[\mathrm{HX}]$, the 4-electron oxidation occurred, to give ring-fused halogenated benzimidazoles (Scheme 12c).

The use of hydroiodic acid (HI) is preferred when oxidative cyclization is required without halogenation [56], due to the relatively smaller electrophilicity of iodine [57]. Fiveand seven-membered cyclizations of 3,6-dimethoxy-2-(cycloamino)anilines with $\mathrm{H}_{2} \mathrm{O}_{2}$ and a catalytic amount of $\mathrm{HI}$ in EtOAc proceeded in high yield (Scheme 13a), but 1,4,6,9tetramethoxyphenazine 17, was unexpectedly formed, as an orange precipitate from sixmembered cyclizations (Scheme 13a,b) [56]. The absence of phenazine $\mathbf{1 7}$ from the five- and seven-membered cyclizations was consistent with previous observations that six-membered oxidative cyclizations are more difficult $[36,43]$. The formation of $\mathbf{1 7}$ was optimized by reducing the amount of EtOAc (the reaction solvent) by four-fold and by decreasing the reaction temperature to room temperature (Scheme 14). Moreover, the isolation of 17 was indicative of a nitrosobenzene intermediate in the conversion of $o$-(cycloamino)anilines to 
ring-fused benzimidazoles via the so-called $t$-amino effect [58]. Syntheses of phenazines involve nitroso intermediates $[56,59,60]$. Recent evidence in the synthesis of ring-fused benzimidazoles, included GC-MS of the reaction mixture (Scheme 14), after $1 \mathrm{~h}$, which revealed EI-MS fragmentation pattern consistent with intermediate 18 [56].

(a) 6-electron oxidation
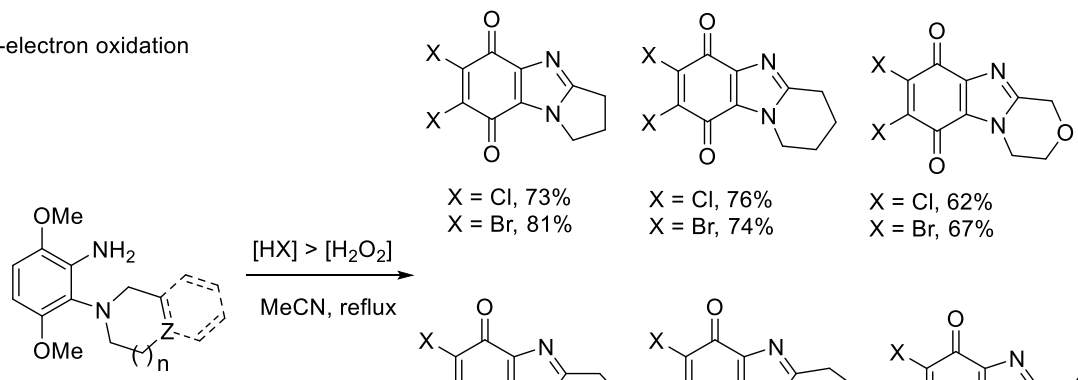

$$
\mathrm{X}=\mathrm{Cl}, 73 \%
$$

$\mathrm{X}=\mathrm{Cl}, 76 \%$

$\mathrm{X}=\mathrm{Cl}, 62 \%$ $\mathrm{X}=\mathrm{Br}, 81 \%$

$$
\mathrm{X}=\mathrm{Br}, 74 \%
$$

$\mathrm{X}=\mathrm{Br}, 67 \%$

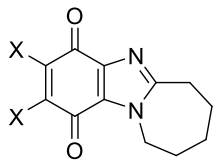

$\mathrm{X}=\mathrm{Cl}, 80 \%$ $\mathrm{X}=\mathrm{Br}, 86 \%$<smiles>[X]C1=C([X])C(=O)c2c(nc3n2CCCCCC3)C1=O</smiles>

$$
\mathrm{X}=\mathrm{Cl}, 54 \%
$$

$\mathrm{X}=\mathrm{Br}, 92 \%$

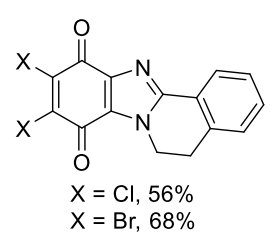

(b) 6-electron oxidation
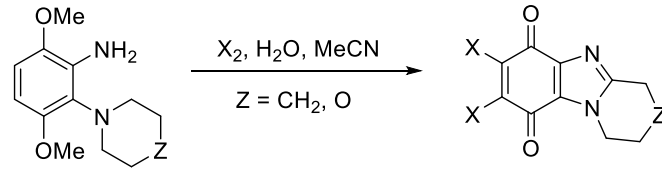

$\mathrm{X}=\mathrm{Cl}, 41-71 \%$ $\mathrm{X}=\mathrm{Br}, 71-90 \%$

(c) 4-electron oxidation
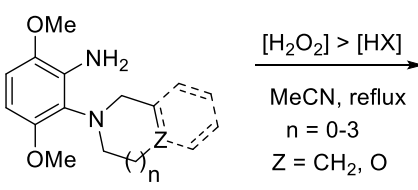

$\mathrm{HX}=\mathrm{HCl}$ or $\mathrm{HBr}$ $\mathrm{X}_{2}=\mathrm{Cl}_{2}$ or $\mathrm{Br}_{2}$

Scheme 12. One-pot transformations of anilines to halogenated ring-fused benzimidazolequinones using (a) $\mathrm{H}_{2} \mathrm{O}_{2} / \mathrm{HX}$, (b) $\mathrm{Cl}_{2}$ and $\mathrm{Br}_{2}$ with water, and (c) $\mathrm{H}_{2} \mathrm{O}_{2} / \mathrm{HX}$ without quinone formation [55].

(a)<smiles>CCOC(=O)CCCC(=O)O</smiles>

(b)

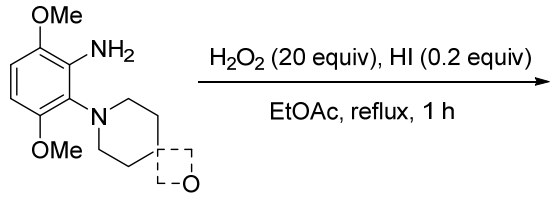<smiles>COc1ccc(OC)c2c1nc1n2CC2CCCC12</smiles>

$\mathrm{n}=1,89 \%$ $\mathrm{n}=2,72 \%$ $\mathrm{n}=3,91 \%$<smiles>COc1ccc(OC)c2nc3c(OC)ccc(OC)c3nc12</smiles>

$17,12 \%$ (only when $n=2$ )<smiles>COc1ccc(OC)c2c1nc1n2CCC2(COC2)C1</smiles>

$74 \%$<smiles>COc1ccc(OC)c2c1nc1n2CCOC1</smiles>

$69 \%$<smiles>COc1ccc(OC)c2nc3c(OC)ccc(OC)c3nc12</smiles>

$17,11 \%$<smiles>COc1ccc(OC)c2nc3c(OC)ccc(OC)c3nc12</smiles>

$17,19 \%$

Scheme 13. $\mathrm{H}_{2} \mathrm{O}_{2}$ /HI-mediated (a) five- to seven-membered cyclizations and (b) six-membered cyclizations with phenazine formation [56]. 


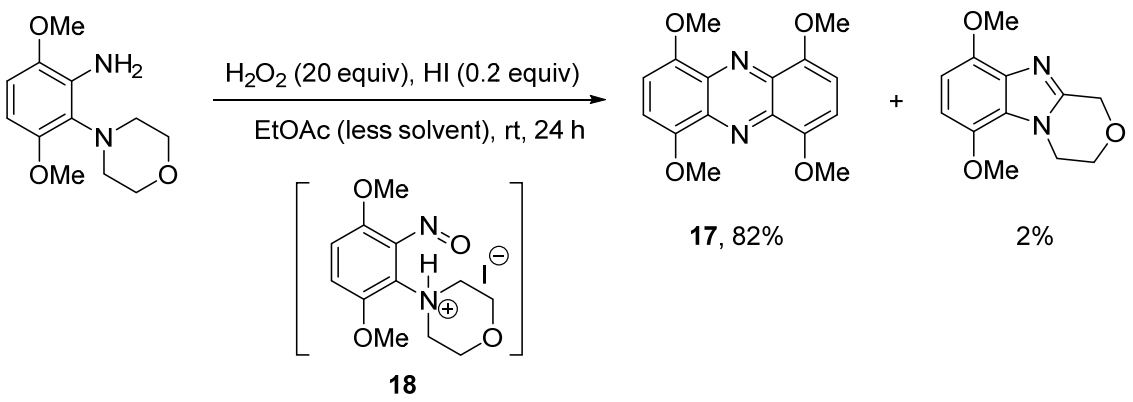

Scheme 14. Optimizing the synthesis of 1,4,6,9-tetramethoxyphenazine 17 [56].

3,4-Dihydro-1H-[1,4] oxazino[4,3-a]benzimidazole can however be prepared in good yield in the absence of acid from 2-(morpholin-4-yl)aniline using Oxone at room temperature (Scheme 15) [61]. Sampling the reaction at short reaction times (within $2 \mathrm{~min}$ ), gave 4-(2-nitrophenyl)morpholine (20), which formed through advantageous air oxidation of the nitroso intermediate 19. The proposed mechanism postulates that $\mathrm{KHSO}_{5}$ (the active ingredient of Oxone) is catalytic, consistent with the use of catalytic amounts of $\mathrm{HI}$ in the $\mathrm{H}_{2} \mathrm{O}_{2}$ /HI-mediated oxidative cyclization of 3,6-dimethoxy-2-(cycloamino)anilines (Schemes 13 and 14) [56].

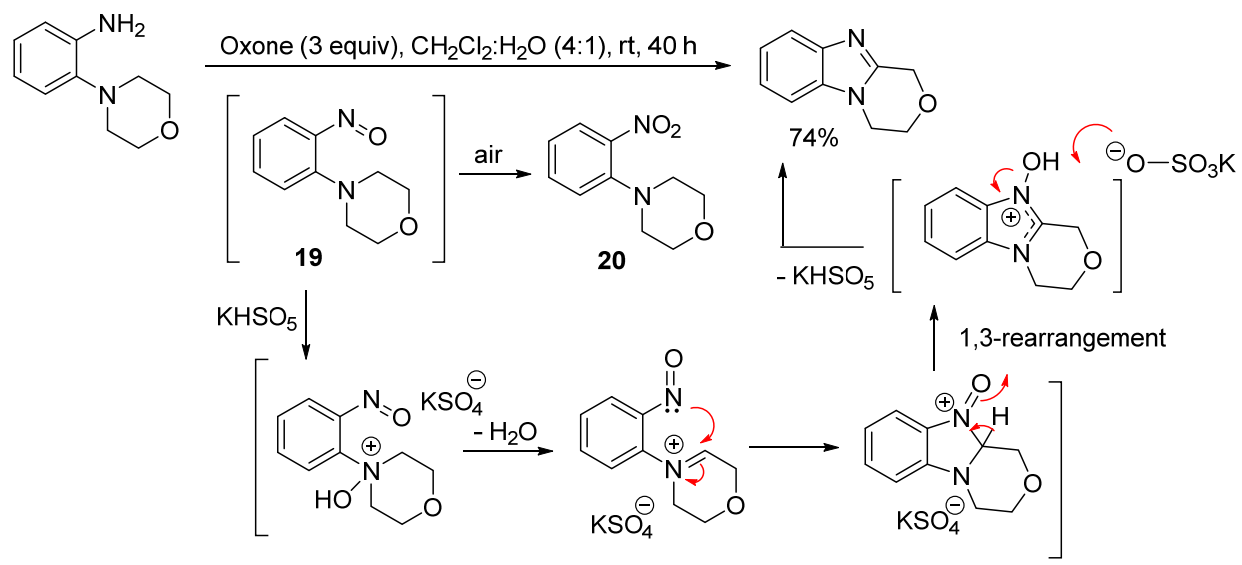

Scheme 15. Oxone-mediated ring-closure of 2-(morpholin-4-yl)aniline [61].

Jana et al. reported one-pot sequential amination of nitrosoarenes with alicyclic amines, followed by oxidative cyclization to give ring-fused benzimidazoles (Scheme 16a-c) [62] Oxone oxidation of commercial anilines gave the nitrosoarene substrates. Nucleophilic aromatic hydrogen substitution $\left(\mathrm{S}_{\mathrm{N}} \mathrm{ArH}\right)$ led to the pyrrolo[1,2-a]benzimidazoles, however piperido- and azepino-analogues required nucleophilic aromatic substitution $\left(\mathrm{S}_{\mathrm{N}} \mathrm{Ar}\right)$ of 2fluoronitrosobenzene to achieve reasonable yields for the [1,2-a] ring-fused benzimidazoles (Scheme 16a). Nucleophilic ipso-substitution of nitrosonaphthols with cyclic amines and subsequent oxidative cyclization delivered a diverse range of ring-fused naphthoimidazoles (Scheme 16b). The authors proposed a mechanism with mass spectrometry detecting the $o$-cyclic amine substituted phenyl hydroxylamine 21, which oxidized to the $o$-cyclic amine substituted nitrosoarene 22 (Scheme 16c). A formal 1,5-hydride shift gave the key iminium ion intermediate $\mathbf{2 3}$ for oxidative cyclization [58]. In contrast to our recent work [43,56,61], the nitrosoarene cyclizations, were carried out using elevated temperatures and under acidic conditions [62]. 
(a)

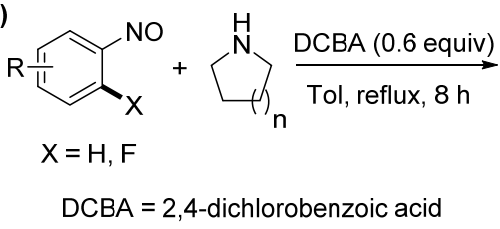<smiles>Cc1cccc2c1nc1n2CCC1</smiles><smiles>CN(C)c1ccc2nc3n(c2c1)CCC3</smiles>

(b)

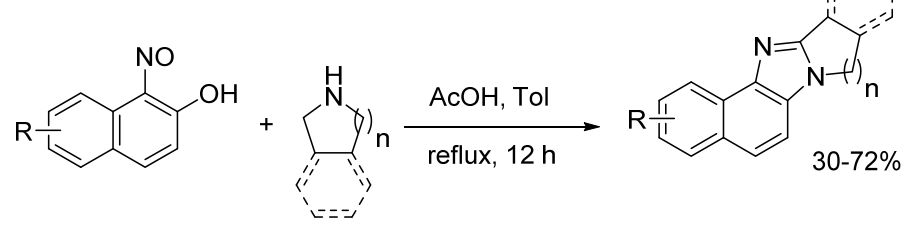

(c)

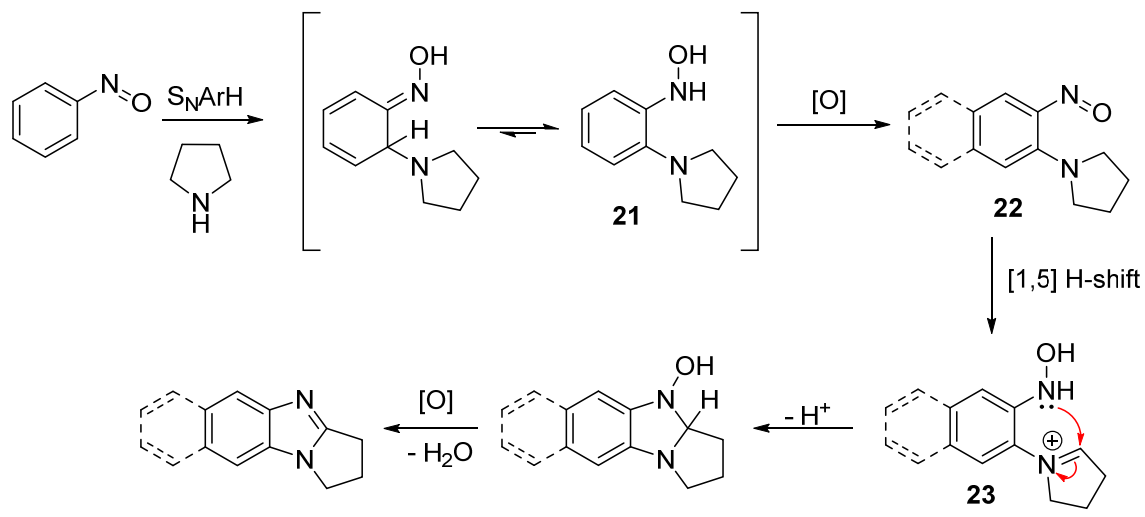

Scheme 16. Sequential aminations of nitrosoarenes to prepare (a) alicyclic ring-fused benzimidazoles, (b) naphthoimidazoles, and (c) the proposed mechanism [62].

\subsubsection{Forming Ring-Fused Imidazobenzimidazoles}

Oxidative cyclizations in this class date back to the 1950s and 1960s [37,63], and Skibo et al. used the performic acid mediated protocol to convert diacetamides to dipyrrolo- and dipyrido-ring-fused imidazo[4,5-f] benzimidazoles, but yields were low (Scheme 17a) [24,25]. One-pot double alkyl radical cyclizations onto the 2- and 6-positions of imidazobenzimidazole gave dipyrrolo-, dipyrido-, and diazepino-ring-fused imidazo[4,5- $f]$ benzimidazoles and imidazo[5,4-f]benzimidazoles in 47-90\% yield (see Section 2.5.3) [26]. However, the radical cyclization route cannot easily give imidazobenzimidazoles containing two different fused rings. Oxone in acid enabled the synthesis of symmetrical and unsymmetrical ring-fused imidazo[4,5-f]benzimidazoles and imidazo[5,4-f]benzimidazoles (Scheme 17b-d) $[27,29,61]$. Yields were higher than older oxidative methods [24,25,37,63], perhaps due to the easier work up, allowing isolation of the imidazobenzimidazole directly from the acidic reaction mixture using precipitation with solid $\mathrm{Na}_{2} \mathrm{CO}_{3}$ [27]. It is noteworthy that 49 and $55 \%$ yield for the spirocyclic oxetane ring-fused isomers, represent $\geq 70 \%$ yield for each ring closure [61]. 
(a)

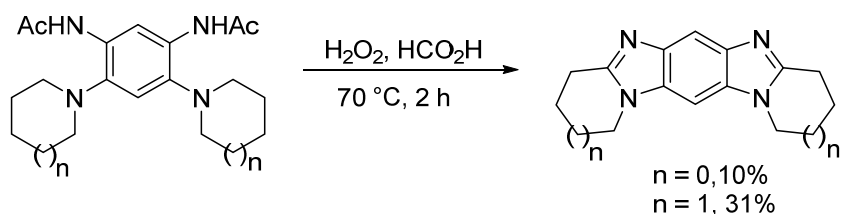

(b)

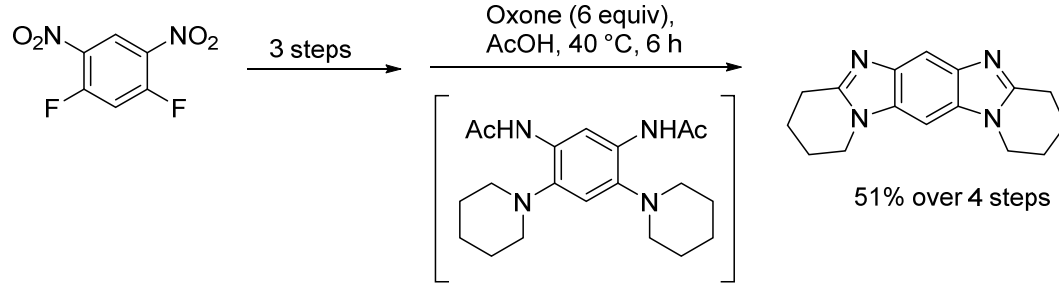

(c)

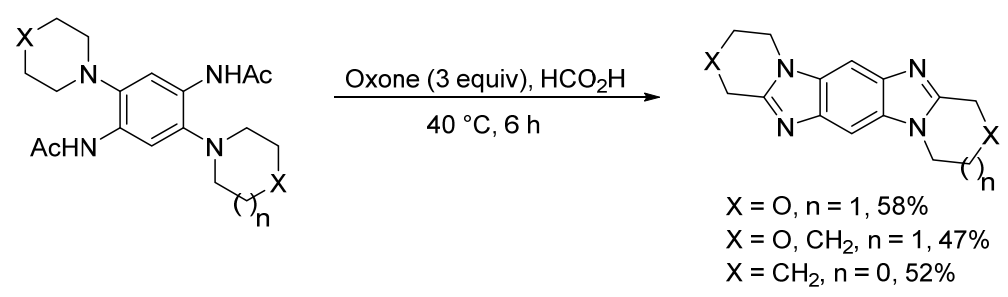

(d)<smiles>[R]OCCNc1cc(NC=[W])c(N2CCCCCC2)cc1N1CCC2(CC1)COC2</smiles><smiles>CC(C)Nc1cc(N2CCC3(CC2)COC3OC(=O)O)c(NC(C)C)cc1N1CCCCC1</smiles>

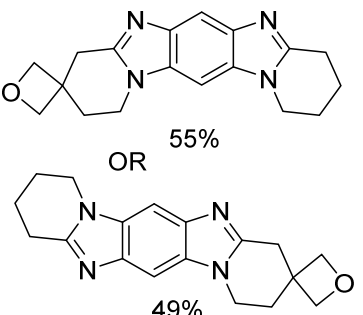

Scheme 17. Oxidative syntheses of imidazo[4,5-f]benzimidazoles using (a) performic acid [24,25] and (b) Oxone [29], and (c) of imidazo[5,4-f]benzimidazoles using Oxone [27], and (d) with fused spirocyclic oxetane ring [61].

Anilide reactant and acidic conditions are a prerequisite for oxidation to the imidazobenzimidazole, with attempts to cyclize 4,6-di(piperidin-1-yl)-1,3-phenylenediamine (24) giving an intractable mixture (Figure 6) [61]. Meth-Cohn proposed the oxidative cyclization of acetamides to benzimidazole derivatives occurs via the amine- $N$-oxide intermediate 25 [38]. Isolated amine- $N$-oxides undergo acid-mediated benzimidazole and imidazobenzimidazole formation $[27,61]$.<smiles>[R4]CN1CCCCC1c1cc(N2CCCCC2)c(N)cc1N</smiles>

24

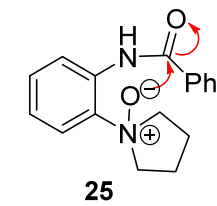

Meth-Cohn orientation

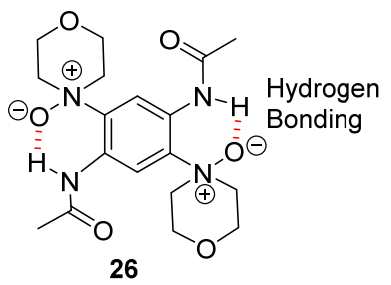

Fagan orientation confirmed by X-ray crystallography

Figure 6. Key chemical structures in resolving the mechanism $[27,37,38]$.

The diamine- $N$-oxide intermediate $\mathbf{2 6}$ for imidazo[5,4-f]benzimidazole formation was isolated by Fagan [27]. The X-ray crystal structure of $\mathbf{2 6}$ showed hydrogen bonding between the amide $\mathrm{NH}$ and the amine $\mathrm{N}$-oxide residues, supporting the absence of the amide $\mathrm{NH}$ peaks in the ${ }^{1} \mathrm{H}$ NMR spectra of solutions of amine $N$-oxides $[27,38,61]$. This is contrary to the orientation of the amine- $\mathrm{N}$-oxide 25 adopted in Meth-Cohn's Polonovski-type reaction 
mechanism [38]. Our proposed mechanism begins with oxidation of the cyclic amines of diacetamide 27 to the Fagan amine- $N$-oxide orientation 26 (Scheme 18). Protonation in acidic media gives the imidols, upon loss of water. The double intramolecular nucleophilic imidol addition onto the iminum ion leads to the ring-fused imidazo[5,4- $f$ ]benzimidazole [27].
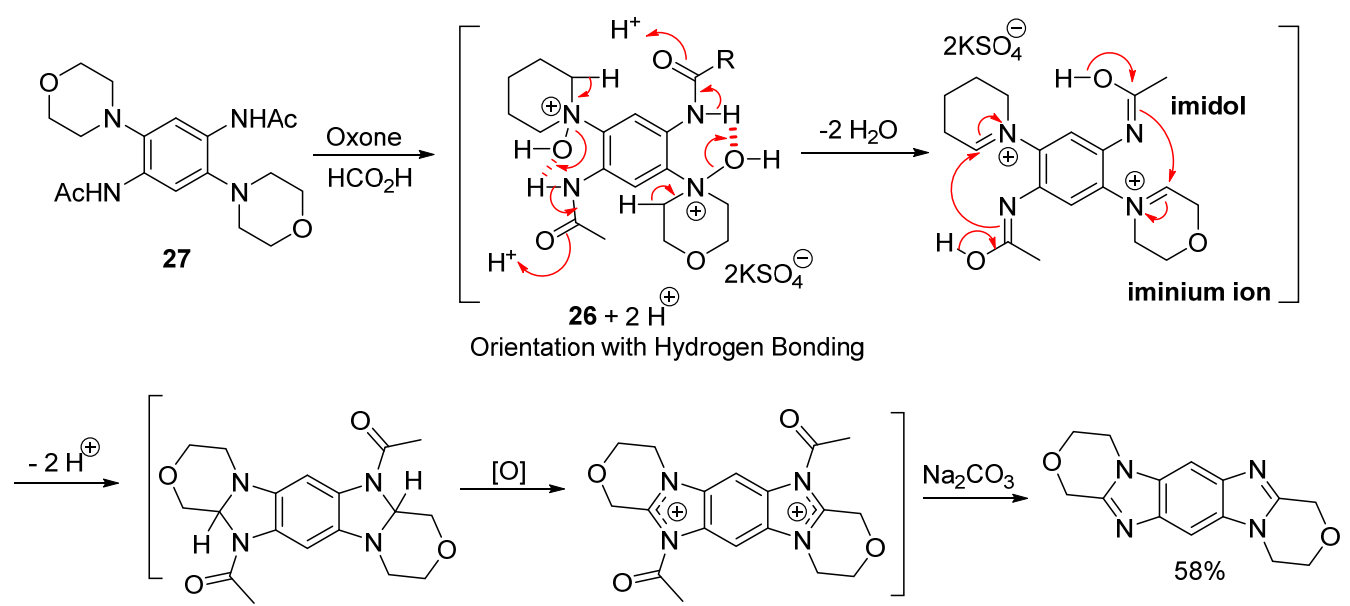

Scheme 18. Mechanism for oxidation $o$-(cycloamino)acetamide to imidazobenzimidazole [27].

An acid-catalyzed cyclization mechanism was proposed for conversion of dimorpholine $\mathrm{N}$-oxide 26 to the [1,4] oxazino[4,3-a]benzimidazole (Scheme 19a) [27]. In the absence of an external oxidant, oxidation is possible through the internal conjugated system. $\mathrm{MsOH}$ allowed conversion of amine $\mathrm{N}$-oxide 28 to the imidazo[4,5- $f$ ] benzimidazole, where presumably another molecule of $\mathbf{2 8}$ acts as oxidant (Scheme 19b) [61].

(a)<smiles>O=C(Nc1ccccc1)c1ccccc1Nc1ccccc1N1CCOCC1</smiles>

(b)<smiles>CC(C)(C)C(=O)Nc1cc2nc3n(c2cc1N1CCCCC1)CCCC3</smiles>
28

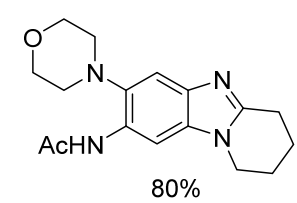

$80 \%$

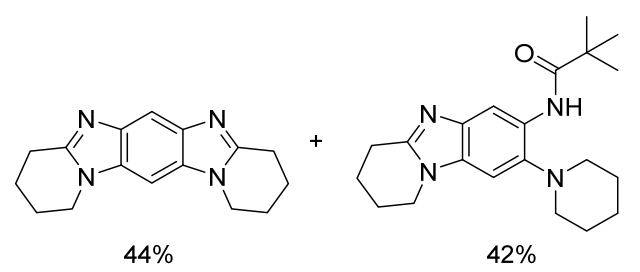

Scheme 19. Acid-mediated cyclization of amine N-oxides to (a) benzimidazole [27] and (b) imidazo[4,5- $f$ ]benzimidazole [61].

\subsection{Reductions of Nitrobenzene-o-Cycloamines (Route B)}

The reduction under acidic conditions of the aromatic nitro-group with cyclization onto the adjacent cycloamine substituent dates to the 1960s and employ $\mathrm{ZnCl}_{2} / \mathrm{Ac}_{2} \mathrm{O}$ [16, 64,65], $\mathrm{TiCl}_{3} / \mathrm{HCl}$ [66], and $\mathrm{Fe} / \mathrm{AcOH}$ [67]. There are cyclizations using Pd-catalysis with $\mathrm{CO}$ [68] or $\mathrm{H}_{2}$ [69]. Recent metal-free conditions use visible light, phenylthiourea as catalyst and $\mathrm{PhSiH}_{3}$ as reductant [70], and electrochemical cyclizations [52]. Thermal annulation using nitrobenzene substrates are possible with neat 1,2,3,4-tetrahydroisoquinoline (THIQ) (Scheme 20a) [71], and cyclizations occur using $\mathrm{I}_{2} / \mathrm{HCO}_{2} \mathrm{H}$ [72] (Scheme 20b). For the former reaction, the authors speculated on THIQ acting as a hydride donor after the initial $\mathrm{S}_{\mathrm{N}} \mathrm{Ar}$ and redox cyclization, while $\mathrm{HI}$ generated in situ, is the active catalytic species in the latter reaction, acting as a strong Brønsted acid and reductant [71,72]. 
(a)<smiles>[R]c1ccc2c(c1)N=C1C3=CC=CC=C2N3Cc2ccccc21</smiles>

(b) $\mathrm{HCO}_{2} \mathrm{H}+\mathrm{I}_{2} \longrightarrow 2 \mathrm{HI}+\mathrm{CO}_{2}$

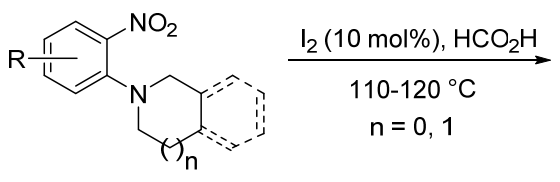<smiles>c1ccc2c(c1)CCn1c-2nc2ccccc21</smiles><smiles>[R]c1ccc2c(c1)nc1n2CCCC1</smiles>

$\mathrm{R}=\mathrm{H}, 75 \%$

$\mathrm{R}=\mathrm{OMe}, 89 \%$

$\mathrm{R}=\mathrm{Cl}, 83 \%$<smiles>c1ccc2c(c1)nc1n2CCOC1</smiles>

Scheme 20. Reductive cyclizations using (a) thermal conditions [71] and (b) $\mathrm{I}_{2} / \mathrm{HCO}_{2} \mathrm{H}$ [72].

2.3. Using Aromatic Amidines, Lactams, and Isothiocyanates (Route C)

Non-redox cyclizations of $o$-haloarylamidines give ring-fused benzimidazoles, using $\mathrm{CuI}$ as catalyst [73,74] (Scheme 21a) or strong base (Scheme 21b) [8,75], where nitrogen displaces the $o$-halogen. Pyrrolo[1,2- $a$ ] benzimidazole was reported from an $o$-lactam substituted aniline cyclization using di-t-butyl sulfoxide/NBS via an aza-Wittig type-reaction (Scheme 21b) [76]. 1-(2-Isothiocyanatophenyl)pyrrolidines cyclize under thermal acidic conditions to benzimidazothiazepines (Scheme 21c) [77].

(a)

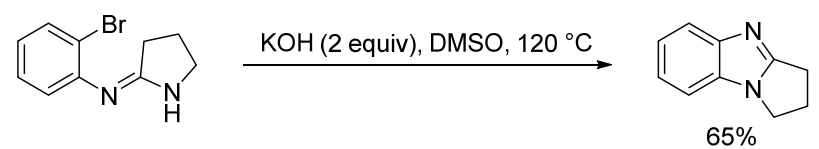

(b)

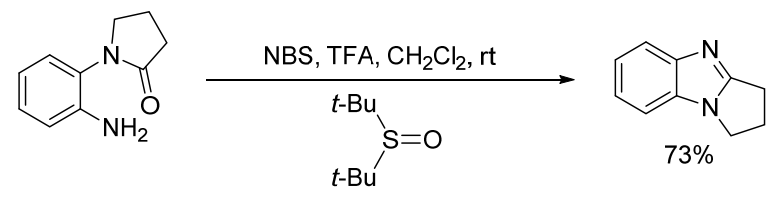

(c)

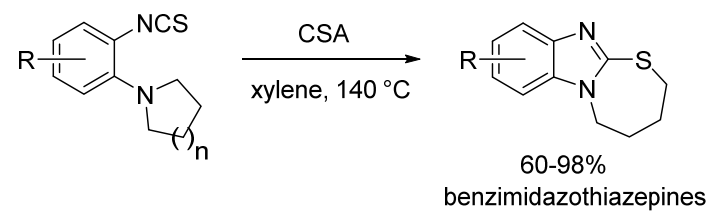

Scheme 21. Synthesis from (a) $o$-haloarylamidine [75], (b) a lactam derivative of $o$-phenyldiamine [76], and (c) a rearrangement of aryl isothiocyanates [77].

Hypervalent iodine(III) reagents allow cyclization of aryl amidines onto non-functionalized benzenes (leaving group $=\mathrm{H}$ ) $[78,79]$. The overall dehydrogenative process is proposed to proceed via a homolytic aromatic substitution (HAS) of nitrogen-centered radicals giving pyrrolo- and pyrido[1,2-a]benzimidazoles (Scheme 22a) [78]. Kosher's reagent (PhI(OH)OTs) 
gave a range of thiazino and oxazino ring-fused benzimidazoles (Scheme 22b) [79]. The oxazino ring-fused benzimidazole required a longer reaction time, and the use of $4 \AA$ molecular sieves.

(a)

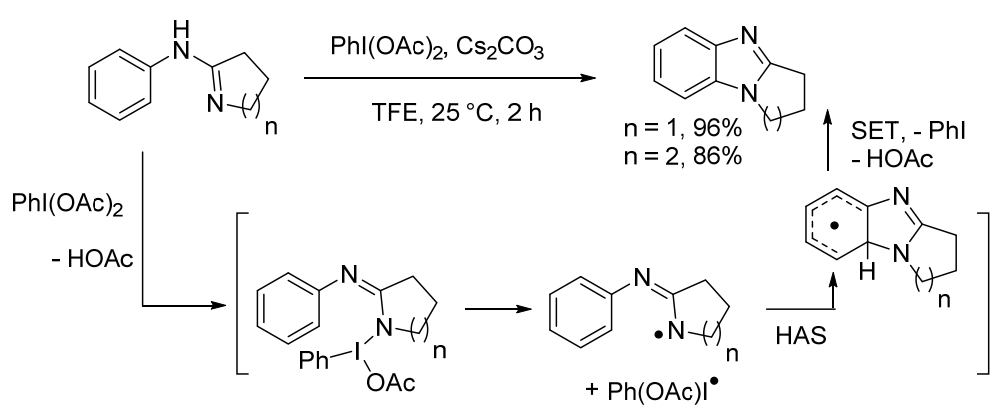

(b)
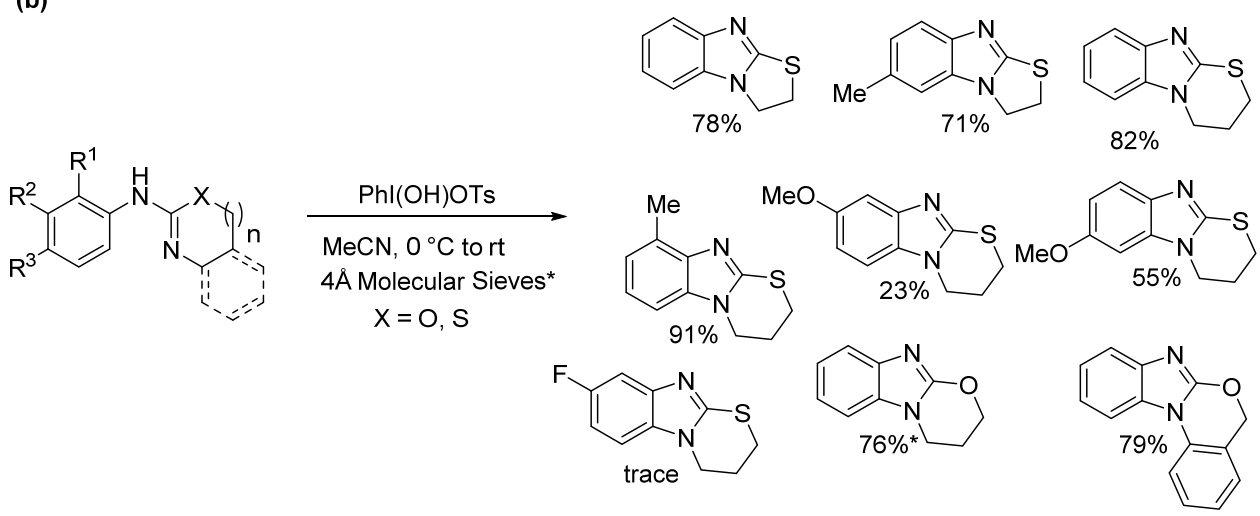

Scheme 22. Cyclization of aryl amidines using (a) phenyliodine(III) diacetate [78] and (b) Kosher's reagent [79].

A combination of Chan-Lam and Ullmann type couplings were said to give the fully unsaturated pyrido[1,2-a]benzimidazoles using 2-aminopyridine and 2-iodoarylboronic acids via an amidine intermediate (Scheme 23) [80].

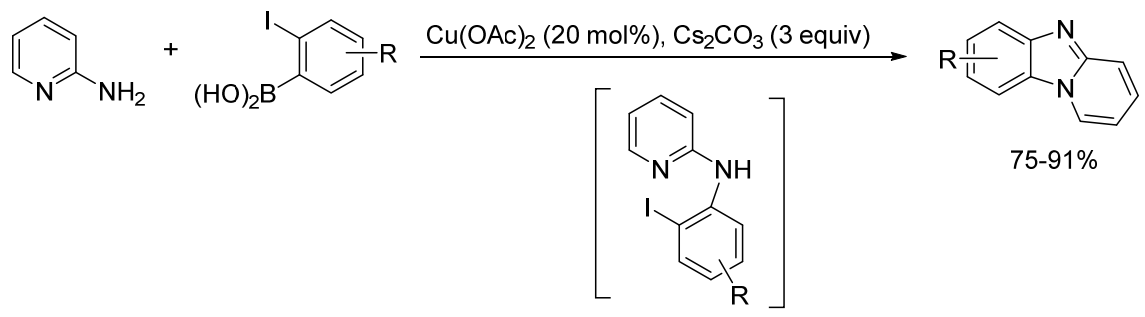

Scheme 23. Synthesis of pyrido[1,2-a] benzimidazoles via amidine intermediates [80].

\subsection{Condensations (Route D)}

This includes the traditional bimolecular condensation of 1,2-phenylenediamines with aldehydes (Scheme 24) [81,82]. Rh-catalyzed cyclization of $\mathrm{N}$-alkenyl-1,2-diaminobenzenes with $\mathrm{CO} / \mathrm{H}_{2}$ gas gave alicyclic ring-fused benzimidazoles via a hydroformylation intermediate [83]. 


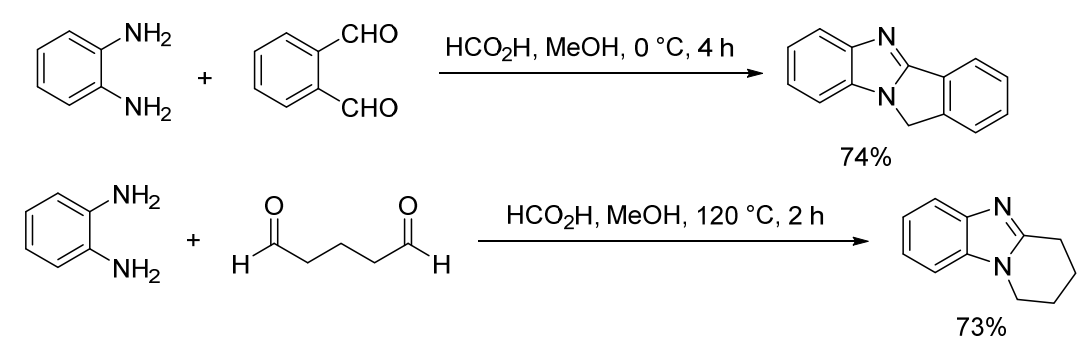

Scheme 24. Acid-catalyzed condensation of 1,2-phenylenediamine with $o$-phthaldehyde and glutaraldehyde [82].

\subsection{Annulations onto Benzimidazoles (Route E)}

A widely reported category for the synthesis of ring-fused benzimidazoles is annulations onto the 1- and 2-positions of benzimidazoles. This section reviews syntheses over the past 20 years, sub-divided according to the employed reaction (type) conditions.

\subsubsection{Base-Mediated Methods}

Early examples of annulation of the benzimidazole moiety cyclized 2-haloalkylbenzimidazoles under basic conditions through $\mathrm{N}-1$ benzimidazole deprotonation to give pyrrolo-, pyrido- and azepino[1,2-a]benzimidazoles [84,85]. Bromoethylsulfonium salt disintegrated under basic conditions with loss of diphenyl sulfide, upon reaction with benzimidazole-2-methanols to give oxazino[4,3-a] benzimidazoles (Scheme 25) [86]. Extension of the latter sulfur ylide approach, achieved thiazino- and piperazino-adducts, but in lower yields.

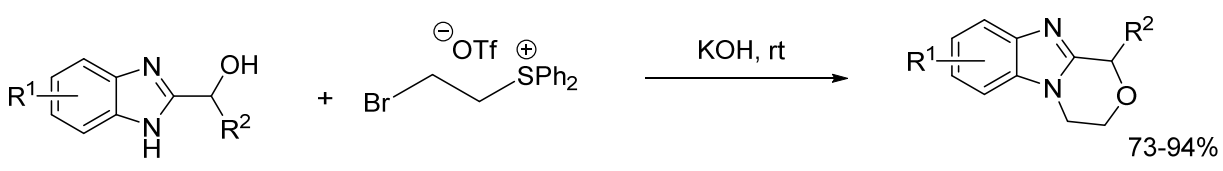

Scheme 25. Annulations [4 +2 ] of benzimidazoles using bromoethylsulfonium salt [86].

\subsubsection{Transition Metal and Lewis Acid Catalyzed Methods}

$\mathrm{InCl}_{3}$-catalyzed the synthesis of benzimidazole-fused 1,4-oxazepines by intramolecular addition of a pendant alcohol onto an in situ-generated imine (Scheme 26) [87].

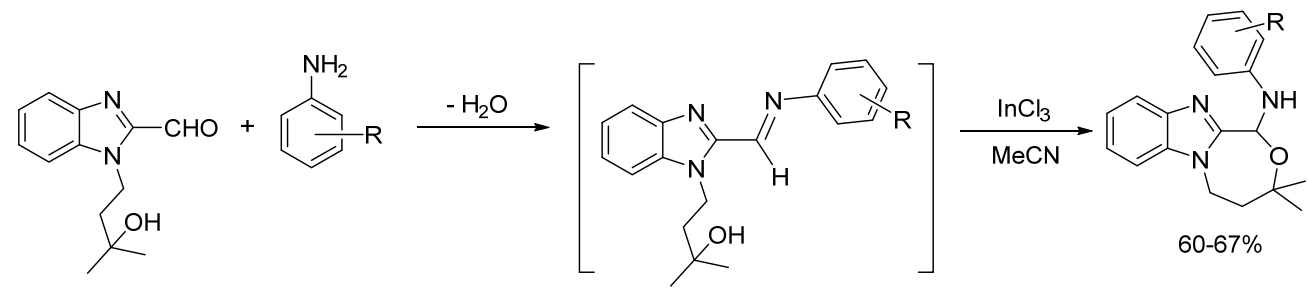

Scheme 26. Synthesis of benzimidazole-fused 1,4-oxazepines [87].

Starting from 2-arylbenzimidazoles and aryl iodides, a tandem Pd(II)-catalyzed C-H arylation and aerobic oxidative $\mathrm{C}-\mathrm{H}$ amination sequence gave a variety of benzimidazolefused phenanthridines (Scheme 27) [88]. Arylated intermediate 29 underwent $\mathrm{C}-\mathrm{H}$ activation in a seven-membered palladacycle with the nitrogen of benzimidazole to yield the aminated products. 
<smiles>[R]c1cc2[nH]c([NH3+])nc2c([R1])c1[R]</smiles><smiles>Ic1cc[R]cc1</smiles>
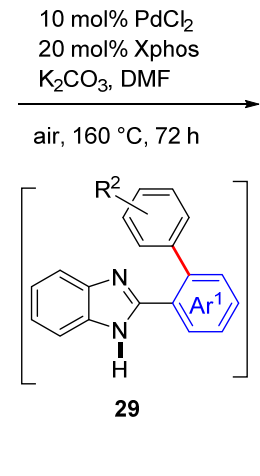

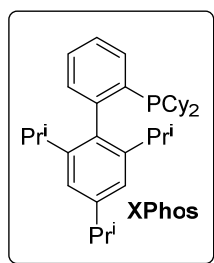

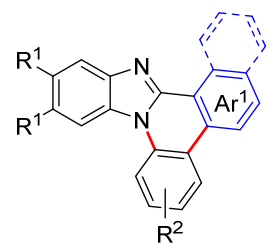

$\mathrm{R}^{1}=\mathrm{H}, \mathrm{Me}, \mathrm{Cl}$ $\mathrm{R}^{2}=\mathrm{H}, \mathrm{Me}, \mathrm{OMe}, \mathrm{Ph}, \mathrm{F}$ $35-90 \%$

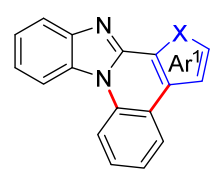

$\mathrm{X}=0,64 \%$ $\mathrm{X}=\mathrm{S}, 85 \%$

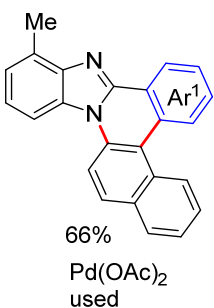

Scheme 27. Pd(II)-catalyzed synthesis of benzimidazole-fused phenanthridines [88].

There are several transition metal mediated benzimidazole-2-CH activated annulations including onto benzimidazole $N$-alkenyl [89-91] and $N$-alkynyl [92] substituents, with high entantioselectivity also achieved $[90,91]$. These include the use of chiral Ni/JoSPOphos manifolds (Scheme 28) [91].

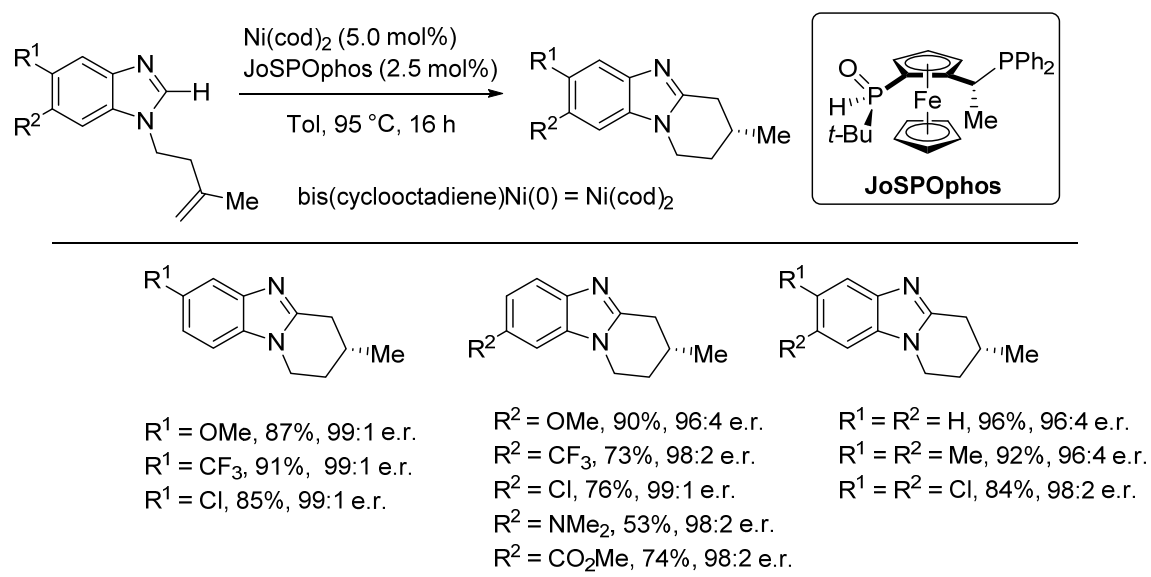

Scheme 28. Asymmetric pyrido[1,2-a]benzimidazole syntheses [91].

$\mathrm{Ru}(\mathrm{II})$-catalyzed [4+2] annulations of 2-arylbenzimidazole with styrenes yielded benzimidazo[2,1-a]isoquinolines (Scheme 29) [93].
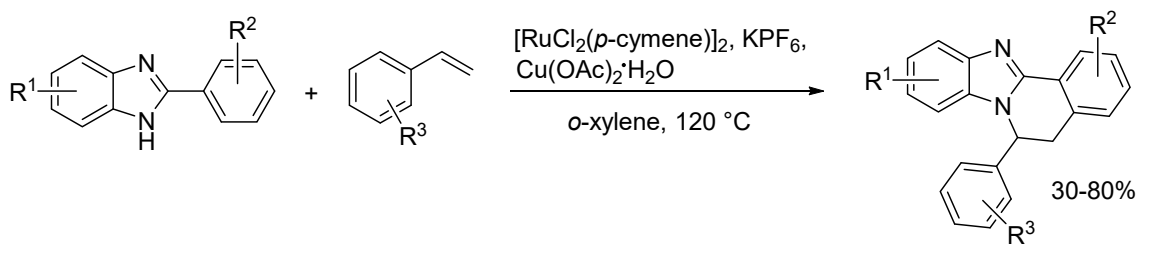

Scheme 29. Annulations [4+2] of benzimidazoles using $\mathrm{Ru}(\mathrm{II})-\mathrm{NH}$ and $\mathrm{CH}$ activation [93].

DeBoef et al. employed $\mathrm{Pd}(\mathrm{II}) / \mathrm{Cu}(\mathrm{I})$ catalysis with the oxidant of $\mathrm{Cu}(\mathrm{OAc})_{2}$ to effect oxidative dehydrogenative coupling of 1-benzyl substituted benzimidazoles (Scheme 30a) [94]. The Pd(II) C-H aryl-activation of 2-phenylbenzimidazoles with C-N coupling of two benzimidazole fragments gave benzimidazoquinazolines, with $\mathrm{Cu}(\mathrm{OAc})_{2}$ or air being the terminal oxidants (Scheme 30b) [95]. 
(a)

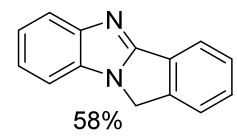<smiles>CC(C)(C)Cn1c(-c2ccc(Cl)cc2)nc2ccccc21</smiles>

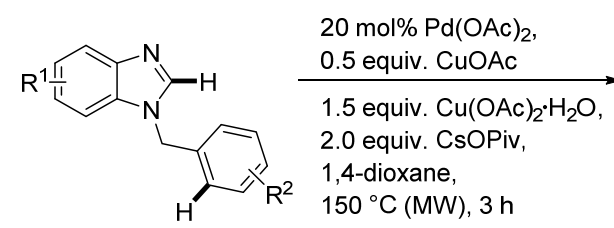<smiles>Cc1cc2nc3n(c2cc1C)Cc1ccccc1-3</smiles><smiles>COc1ccc2c(c1)C[13CH2]C21Cn2c1nc1ccccc12</smiles><smiles>O=[N+]([O-])c1ccc2c(c1)nc1n2Cc2ccccc2-1</smiles><smiles>Cc1cc2nc3n(c2cc1C)Cc1cc(C(F)(F)F)ccc1-3</smiles>

(b)

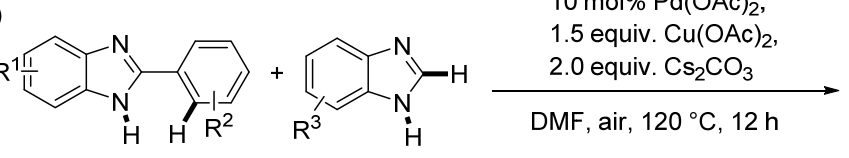

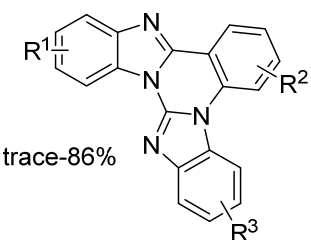

Scheme 30. Pd-catalyzed dehydrogenative cross-couplings to give (a) $11 H$-isoindolo[2,1-a]benzimidazoles [94] and (b) benzimidazoquinazolines [95].

CuI-catalyzed an aminothiolation of 1,1-dibromoalkenes (Scheme 31a) [96]. The mechanism involves initial in situ dehydrobromination of the 1,1-dibromoalkene to 1bromoalkyne. $\mathrm{N}$-alkylation of the aromatic alkene and $\mathrm{Cu}$-catalyzed $\mathrm{C}-\mathrm{S}$ coupling or 5-endodig cyclization gives the annulated benzimidazole. More recently, 2-(2-bromoaryl)- and 2-(2-bromovinyl)benzimidazole substrates were coupled with cyanamide using CuI to give 2-aminoquinazoline and 2-aminopyrimidine hybrid structures (Scheme 31b) [97]. Similar conditions allowed CuI-mediated coupling and cyclization between 2-(2-bromoaryl)indoles and 2-aminoazoles [98], including 2-aminobenzimidazoles with loss of ammonia to give indole analogues of Scheme 30b adducts [95].

(a)<smiles>Sc1nc2ccccc2[nH]1</smiles><smiles>[R]c1ccc(C=C(Br)Br)cc1C(C)(Br)C(C)(C)C</smiles>

Cul (10 mol\%), DMEDA (15 mol\%) TBAF, DMF, $65^{\circ} \mathrm{C}$
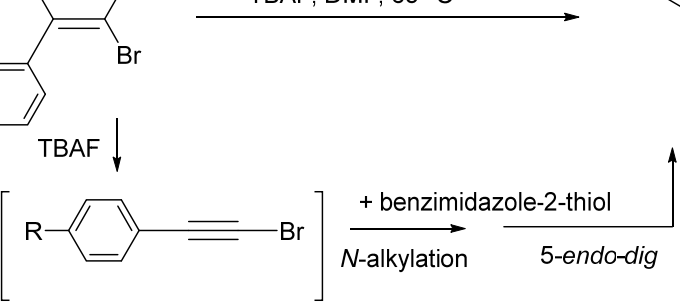

(b)
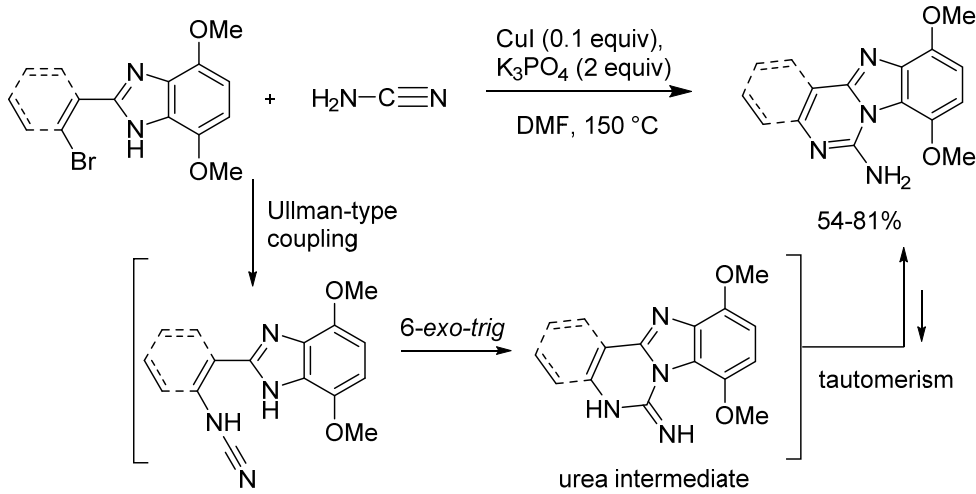

Scheme 31. CuI-catalyzed annulations onto N-1 of benzimidazole using (a) 1,1-dibromoalkenes [96] and (b) cyanamide [97]. 
A Pd-catalyzed reductive cyclization gave a variety of benzimidazole-fused thiazocine scaffolds (Scheme 32), but also thiazonines (9-membered rings), and thiazecines (10-membered) having an exocyclic double bond [99]. Ammonium formate is the hydrogendonor.
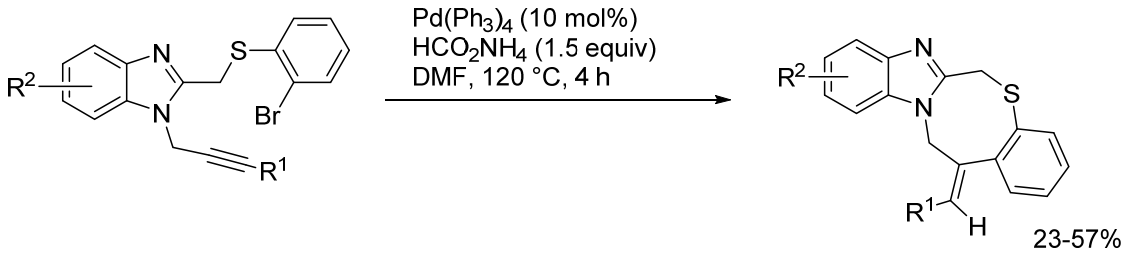

Scheme 32. Pd-catalyzed macrocyclization to give benzimidazole-fused thiazocine [99].

\subsubsection{Radical Cyclization Methods}

We have reported annulations utilizing the benzimidazole-2-position to form nucleophilic ylide for condensation reactions [100,101] and the benzimidazol-2-yl radical for initiator-free photochemical HAS (Scheme 33a) [102]. Photochemical intramolecular HAS of the imidazol-2-yl radical are superior to analogous $\mathrm{Bu}_{3} \mathrm{SnH}$-mediated reactions [103].

(a)

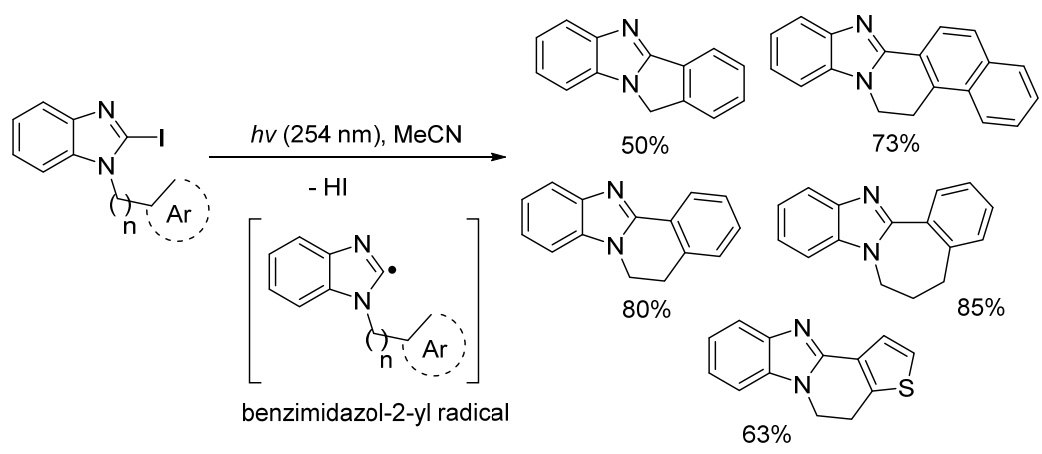

(b)

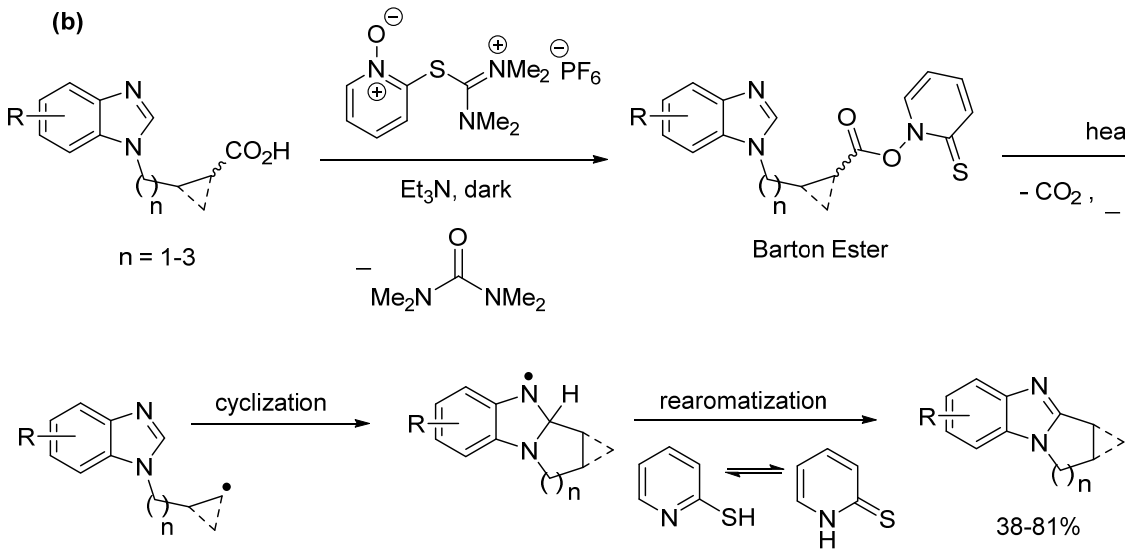

Scheme 33. Radical initiator-free HAS using (a) UV-light [102] and (b) Barton ester intermediates [104].

$\mathrm{Bu}_{3} \mathrm{SnH}$-mediated chain reactions enabled 6-exo-trig cyclizations of aryl or pyridinyl radicals to yield a variety of aromatic-ring fused benzimidazoles [23,105] (Scheme 34a). HAS using alkyl radical cyclizations onto benzimidazole [21], imidazo[4,5- $f$ ]benzimidazole and imidazo[5,4- $f$ ]benzimidazole [26] proceed as non-chain reactions [106-108] requiring full equivalents of $\mathrm{Bu}_{3} \mathrm{SnH}$ and azo-initiator to give the aromatic products in moderate to high yields (Scheme 34b). Single ring-fused imidazo[5,4- $f$ ]benzimidazolequinones for anti-cancer evaluation studies, were also derived via this radical cyclization route (Scheme 34c) [28]. The latter cyclization required a substrate prepared by two separate alky- 
lations of imidazobenzimidazole using 1-chlorobutane and 1-chloro-4-(phenylselenyl)butane. For $\mathrm{Bu}_{3} \mathrm{SnH}$-mediated reactions, slow addition of radical initiators is required, which prevents $\mathrm{Bu}_{3} \mathrm{SnH}$ reduction of the cyclizing radical. Camphorsulfonic acid (CSA) or $\mathrm{Ac}_{2} \mathrm{O}$ are added to more difficult cyclizations, to activate the benzimidazole-2-position towards nucleophilic radical addition $[21,26]$. For the HAS onto imidazobenzimidazoles (Scheme 34b,c), exposing the reaction mixture to air for part of the reaction time gave higher yields, since oxygenated radicals are thought to be involved in the oxidative re-aromatization (or hydrogen atom-abstraction) step [26,108].

(a)<smiles>[R]c1ccc([R])c2c1nc(-c1[X]c3ccccc3cc1)n2CC=C</smiles>

$\mathrm{X}=\mathrm{C}, \mathrm{N}$ $\mathrm{R}=\mathrm{H}, \mathrm{OMe}$

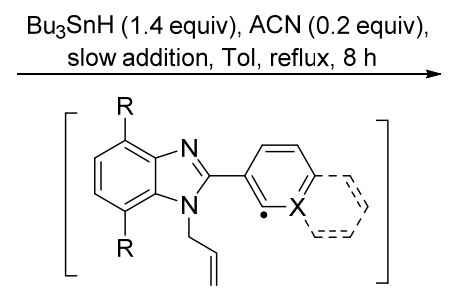

$\mathrm{Bu}_{3} \mathrm{SnH}$ (1.4 equiv), $\mathrm{ACN}$ (0.2 equiv),

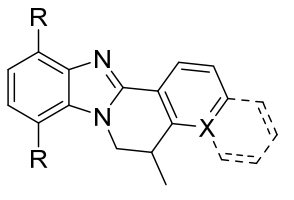

$70-78 \%$

(b)

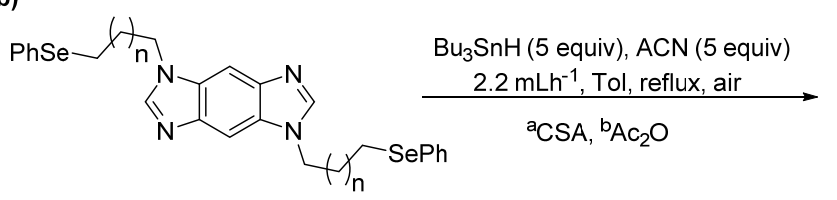

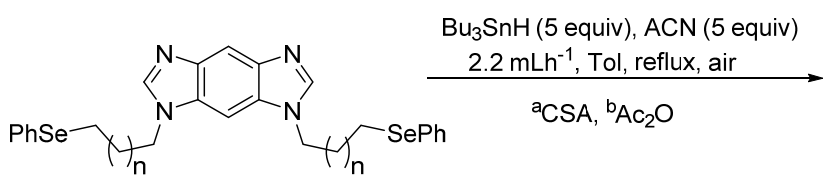

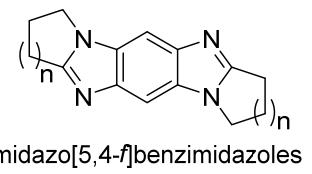
$\mathrm{n}=1(47 \%)^{\mathrm{a}}$ $\mathrm{n}=2(90 \%)$ $n=3(54 \%)^{b}$

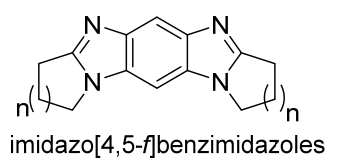

$\mathrm{n}=1(48 \%)^{\mathrm{a}}$ $\mathrm{n}=2(81 \%)$ $\mathrm{n}=3(48 \%)^{\mathrm{b}}$

(c)

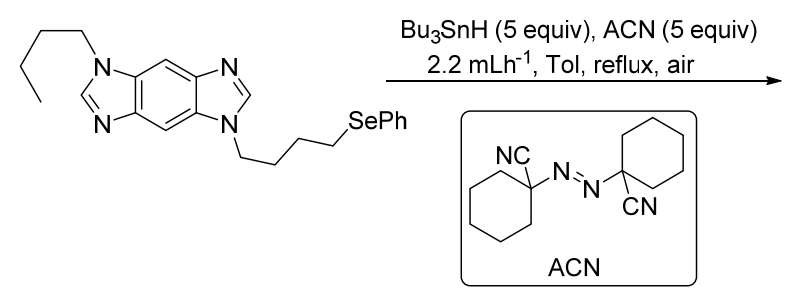

Scheme 34. $\mathrm{Bu}_{3} \mathrm{SnH}$-mediated formation of ring-fused benzimidazoles using (a) chain reaction $[23,105]$, and non-chain reaction (b) double [26] and (c) single [28] HAS.

An alternative approach to HAS, is initiator-free, using in situ generated Barton ester intermediates derived from robust and readily accessible carboxylic acid substrates, giving five- to seven-membered alkyl and cyclopropyl radical cyclizations via a chain reaction mechanism (Scheme 33b) [104,109]. Most recently, benzimidazo[2,1-a] isoquinolin-6-ones were prepared by the addition of methyl radicals onto $N$-methacryloyl-2-phenylbenzimidazoles 30 using di-tert-butyl peroxide (DTBP) initiator (Scheme 35) [110]. The tertiary adduct radical undergoes six-membered cyclization followed by oxidation of the derived cyclized radical. Earlier, tert-butyl radicals generated from pivalic acid and several other carboxylic acids with $\mathrm{K}_{2} \mathrm{~S}_{2} \mathrm{O}_{8} / \mathrm{AgNO}_{3}$ initiated an analogous cascade [111]. 


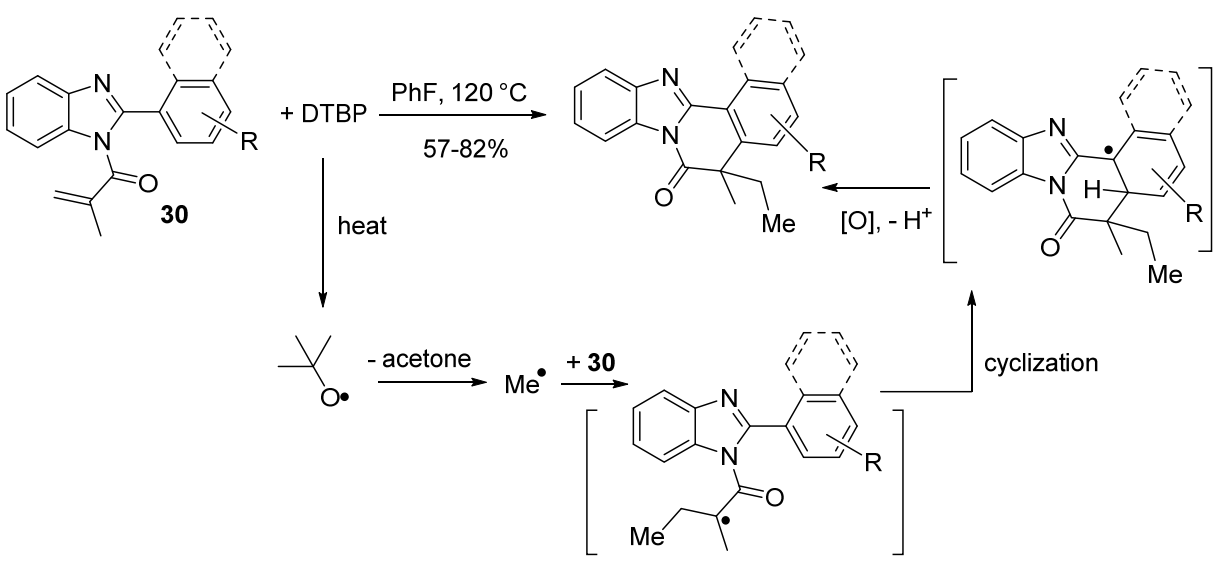

Scheme 35. Di-tert-butyl peroxide (DTBP)-mediated oxidative HAS [110].

\subsubsection{Other Metal-Free Methods}

Mal et al. reported the use of PIFA $\left(\mathrm{PhI}\left(\mathrm{OCOCF}_{3}\right)_{2}\right)$ for six-membered aromatic substitutions via a proposed nitrenium ion intermediate (Scheme 36a) [112]. Cho et al. made the reaction at $\mathrm{N}-1$ of benzimidazole intermolecular, with addition onto aryl isocyanate and aromatic substitution of the carbamoyl-NH to give fused quinazolinones and pyrimidinones (Scheme 36b) [113].

(a)<smiles>[R]c1cc2nc(-c3ccccc3-c3ccccc3[R])[nH]c2cc1[R]</smiles><smiles>[R]c1cc2[nH]c(-c3ccccc3-c3ccccc3[R])nc2cc1[R1]([H])[H]</smiles><smiles>[R]C1=CC2=c3ccccc3=C3c4cc([R])c([R1])cc4N=C(C2=C1)c1c([R])cccc13</smiles>
$82-98 \%$ nitrenium intermediate

(b)

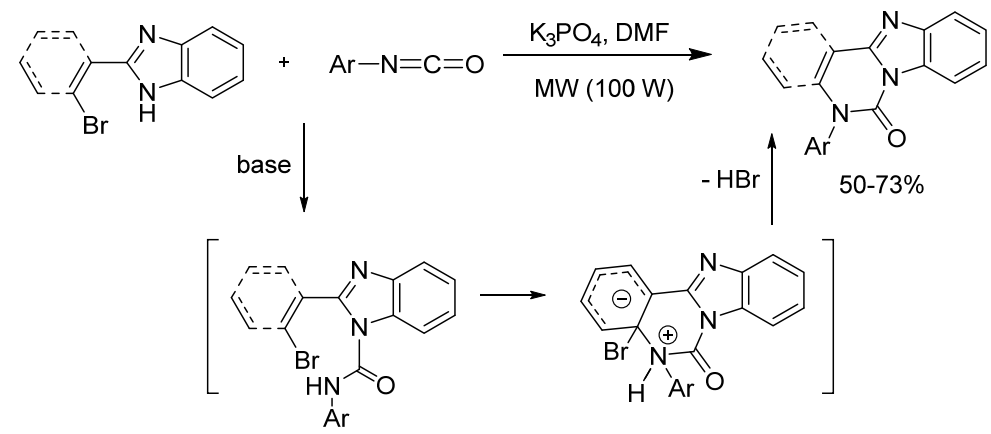

Scheme 36. Annulations onto N-1 of benzimidazole using (a) PIFA [112] and (b) aryl isocyanates [113].

There are now several reports of benzimidazole syntheses using iodine in metal-free procedures $[56,72,114]$. Benz[4,5]imidazo[1,2-a]quinoxaline derivatives were obtained by an $\mathrm{I}_{2-}$ mediated oxidative condensation of 2-(benzimidazol-1-yl)aniline substrates (Scheme 37) [114]. 


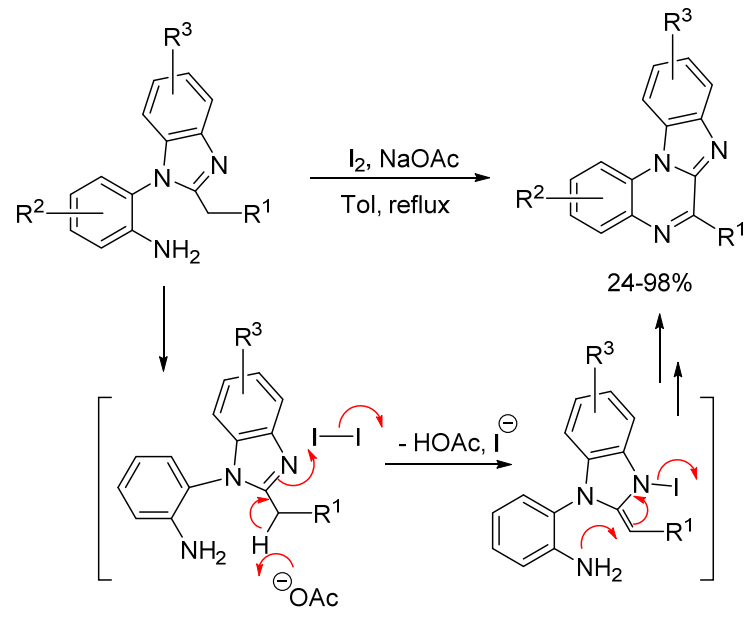

Scheme 37. Condensation of 2-(benzimidazol-1-yl)anilines [114].

\subsubsection{Miscellaneous: Syntheses of Mitomycin Analogues}

We reported the synthesis and anti-cancer evaluation of diazole analogues of MMC derivatives (Figure 3) and related indolequinones [14,21,22,115,116]. The formation of pyrrolo-, pyrido-, azepino- and azocino[1,2-a]benzimidazoles with a fused cyclopropane ring involves $\mathrm{N}$-aziridinyl imines (Eschenmoser hydrazones) undergoing thermolysis with a loss of nitrogen and trans-stilbene (Scheme 38a) $[22,115,116]$. The formation of the aziridinomitosene analogue skeleton was via an intramolecular anionic aromatic ipso-substitution of an aziridinyl functionality onto the benzimidazol-2-yl position (Scheme 38b) [14]. Earlier the 2-phenylsulfanylbenzimidazole precursors gave five to seven-membered ring-fused benzimidazoles using alkyl radical cyclizations with substitution of the radical leaving group at the 2-position [117].

(a)

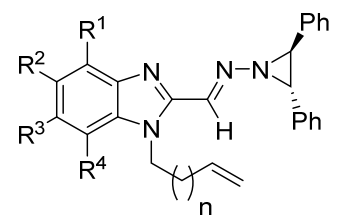

Eschenmoser hydrazone

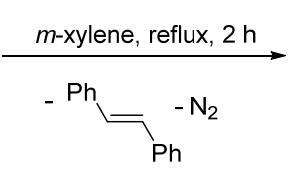

$R^{2}, R^{3}=M e, n=0,70 \%$ $R^{2}, R^{3}=M e, n=1,50 \%$ $R^{2}, R^{3}=M e, n=2,77 \%$

$R^{2}, R^{3}=M e, n=3,11 \%$<smiles>[R]c1nc2c(nc3n2CC3)c([R])c1[R]</smiles>

$\mathrm{R}^{1}-\mathrm{R}^{4}=\mathrm{H}, \quad \mathrm{n}=0,85 \%$ $R^{1}-R^{4}=H, \quad n=1,53 \%$ $\mathrm{R}^{1}, \mathrm{R}^{4}=\mathrm{OMe}, \mathrm{n}=0,68 \%$ $\mathrm{R}^{1}, \mathrm{R}^{4}=\mathrm{OMe}, \mathrm{n}=1,58 \%$

(b)

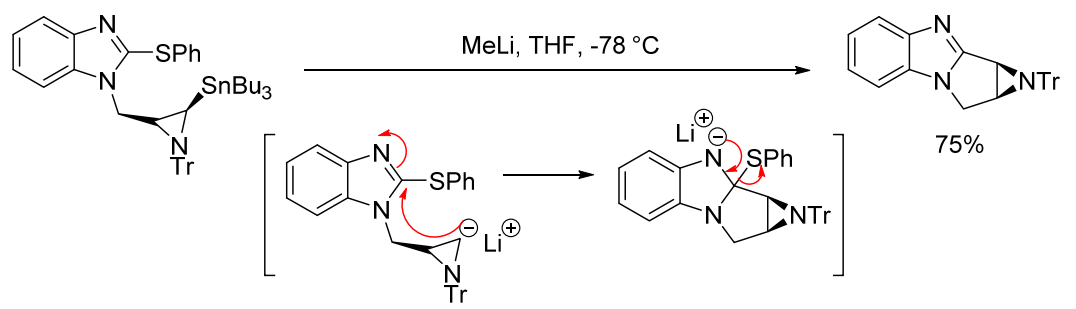

Scheme 38. Synthesis of analogues of (a) cyclopropamitosenes $[22,115,116]$ and (b) aziridinomitosene [14].

\section{Conclusions}

Over the past 20 years, significant advances in the synthesis of ring-fused benzimidazoles have occurred, notably using dehydrogenative coupling and radical cyclization. Transition metal catalysts achieve intramolecular and intermolecular aminations with benzimidazoles, with enantioselectivity for the former. Ring-fused benzimidazoles are prepared 
using hypervalent iodine(III) reagents and elemental iodine under metal-free conditions. There is an increasing use of sustainable and non-metal-mediated protocols, including photochemical, electrochemical, and thermal methods. Mild oxidative conditions tend to be more effective for preparing isoindoline and tetrahydroisoquinoline-fused scaffolds. There are effective methods for incorporating heteroatoms into the fused-ring, including $\mathrm{N}, \mathrm{O}$, and $\mathrm{S}$ atoms, and forming alicyclic rings with additional fused cyclopropane or delicate oxetane and aziridine rings. In terms of versatility, green chemistry, and value for money, it is difficult to beat the use of $\mathrm{H}_{2} \mathrm{O}_{2}$ in traditional oxidative cyclizations of $o$ (cycloamino)anilines. $\mathrm{H}_{2} \mathrm{O}_{2}$ in combination with $\mathrm{HX}$ generates the ordinarily inconvenient elemental halogen $\left(\mathrm{X}_{2}\right)$ in situ, to mediate one-pot oxidative cyclization with halogenation. The latter includes one-pot approaches to potential antitumor ring-fused benzimidazolequinones from readily accessible anilines. Oxone is a cheap alternative, with technical and environmental benefits, including the circumvention of organic waste by-products. Our present work generates $X_{2}$ in situ, by combining Oxone with benign $\mathrm{NaX}$, to carry out onepot halogenation with oxidative demethylation to give the dimeric quinones of ring-fused dimethoxybenzimidazole-benzimidazolequinones (DMBBQs) [118]. The DMBBQ scaffold offers unique regioselective functionalization opportunities for bis-quinone motifs, and these unique dimeric structures require investigation as bioreductive anti-tumor agents.

Mechanisms for ring-fused benzimidazole and imidazobenzimidazole formation via the $t$-amino effect are now better defined. Recent studies have shown that acid and heat are unnecessary for oxidative cyclization via a nitrosobenzene intermediate using $o$-(cycloamino)anilines as substrates for benzimidazole formation. This offers opportunities for further investigations into the synthesis of ring-fused benzimidazoles under nonaggressive ambient conditions using commercial anilines as starting materials. While use of anilide derivatives results in a different mechanism via an amine- $N$-oxide intermediate. The anilide derivative and acidic conditions are mandatory for peroxide-mediated ringfused imidazobenzimidazole preparations. To date ring-fused imidazobenzimidazoles have only been prepared via oxidative cyclizations of anilides and radical cyclizations onto imidazobenzimidazoles, surely new synthetic methods will merge for this interesting scaffold.

Author Contributions: Writing: M.S., D.C., and F.A.; review: S.I.M. and F.A.; conceptualization, editing, supervision, and funding acquisition: F.A. All authors have read and agreed to the published version of the manuscript.

Funding: The Irish Research Council, Government of Ireland Postgraduate Scholarship and Postdoctoral Fellowship respectively funded the research of M.S. and S.I.M., and Kingston University funded the research of D.C.

Institutional Review Board Statement: Not applicable.

Informed Consent Statement: Not applicable.

Data Availability Statement: Not applicable.

Acknowledgments: F.A. thanks his past NUI Galway research students for their many valuable contributions to the synthesis and anti-cancer evaluation of the herein reviewed compounds. F.A. dedicates this review to Leo and Joseph.

Conflicts of Interest: The authors declare no conflict of interest.

\section{References}

1. Brink, N.G.; Folkers, K. Vitamin B12 VI. 5,6-Dimethylbenzimidazole, a. degradation product of vitamin B 12 . J. Am. Chem. Soc. 1949, 71, 2951. [CrossRef]

2. Floyd, J.C.; Holliday, E.R.; Petrow, V. Letters to the Editor. J. Pharm. Pharmacol. 1949, 1, 734-735. [CrossRef]

3. Yadav, G.; Ganguly, S. Structure activity relationship (SAR) study of benzimidazole scaffold for different biological activities: A mini-review. Eur. J. Med. Chem. 2015, 97, 419-443. [CrossRef] [PubMed]

4. Keri, R.S.; Hiremathad, A.; Budagumpi, S.; Nagaraja, B.M. Comprehensive review in current developments of benzimidazolebased medicinal chemistry. Chem. Biol. Drug Des. 2015, 86, 19-65. [CrossRef] 
5. Bansal, Y.; Silakari, O. The therapeutic journey of benzimidazoles: A review. Bioorg. Med. Chem. 2012, 97, 419-443. [CrossRef] [PubMed]

6. Leadbeater, A.J. Plant health management: Fungicides and antibiotics. In Encyclopedia of Agriculture and Food Systems; Van Alfen, N.K., Ed.; Academic Press: Cambridge, MA, USA, 2014; pp. 408-424. [CrossRef]

7. Kojima, T.; Mochizuki, M.; Takai, T.; Hoashi, Y.; Morimoto, S.; Seto, M.; Nakamura, M.; Kobayashi, K.; Sako, Y.; Tanaka, M.; et al. Discovery of 1,2,3,4-tetrahydropyrimido[1,2-a]benzimidazoles as novel class of corticotropin releasing factor 1 receptor antagonists. Bioorg. Med. Chem. 2018, 26, 2229-2250. [CrossRef] [PubMed]

8. Wang, Y.; Liu, W.-J.; Yin, L.; Li, H.; Chen, Z.-H.; Zhu, D.-X.; Song, X.-Q.; Cheng, Z.-Z.; Song, P.; Wang, Z.; et al. Design and synthesis of 4-(2,3-dihydro-1H-benzo[d]pyrrolo[1,2-a]imidazol-7-yl)- $N$-(5-(piperazin-1-ylmethyl)pyridine-2-yl)pyrimidin-2-amine as a highly potent and selective cyclin-dependent kinases 4 and 6 inhibitors and the discovery of structure-activity relationships. Bioorg. Med. Chem. Lett. 2018, 28, 974-978. [CrossRef]

9. Ferraris, D.; Ficco, R.P.; Dain, D.; Ginski, M.; Lautar, S.; Lee-Wisdom, K.; Liang, S.; Lin, Q.; Lu, M.X.-C.; Morgan, L.; et al. Design and synthesis of poly(ADP-ribose) polymerase-1 (PARP-1) inhibitors. Part 4: Biological evaluation of imidazobenzodiazepines as potent PARP-1 inhibitors for treatment of ischemic injuries. Bioorg. Med. Chem. 2003, 11, 3695-3707. [CrossRef]

10. Hoang, H.; Huang, X.; Skibo, E.B. Synthesis and in vitro evaluation of imidazole-based wakayin analogues. Org. Biomol. Chem. 2008, 6, 3059-3064. [CrossRef]

11. Bass, P.D.; Gubler, D.A.; Judd, T.C.; Williams, R.M. Mitomycinoid alkaloids: Mechanism of action, biosynthesis, total syntheses, and synthetic approaches. Chem. Rev. 2013, 113, 6816-6863. [CrossRef]

12. O'Donovan, L.; Carty, M.P.; Aldabbagh, F. First synthesis of $N$-[(aziridin-2-yl)methyl]benzimidazolequinone and analysis of toxicity towards normal and Fanconi anemia cells. Chem. Commun. 2008, 43, 5592-5594. [CrossRef]

13. Fahey, K.; O'Donovan, L.; Carr, M.; Carty, M.P.; Aldabbagh, F. The influence of the aziridinyl substituent of benzimidazoles and benzimidazolequinones on toxicity towards normal and Fanconi anaemia cells. Eur. J. Med. Chem. 2010, 45, 1873-1879. [CrossRef] [PubMed]

14. Bonham, S.; O'Donovan, L.; Carty, M.P.; Aldabbagh, F. First synthesis of an aziridinyl fused pyrrolo[1,2-a]benzimidazole and toxicity evaluation towards normal and breast cancer cell lines. Org. Biomol. Chem. 2011, 9, 6700-6706. [CrossRef]

15. Islam, I.; Skibo, E.B.; Dorr, R.T.; Alberta, D.S. Structure-activity studies of antitumor agents based on pyrrolo[1,2-a]benzimidazoles: New reductive alkylating DNA cleaving agents. J. Med. Chem. 1991, 34, 2954-2961. [CrossRef] [PubMed]

16. Skibo, E.B.; Gordon, S.; Bess, L.; Boruah, R.; Heileman, M.J. Studies of pyrrolo[1,2-a]benzimidazolequinone DT-diaphorase substrate activity, topoisomerase II inhibition activity, and DNA reductive alkylation. J. Med. Chem. 1997, 40, 1327-1339. [CrossRef] [PubMed]

17. Craigo, W.A.; LeSueur, B.W.; Skibo, E.B. Design of highly active analogues of the pyrrolo[1,2-a]benzimidazole antitumor agents. J. Med. Chem. 1999, 42, 3324-3333. [CrossRef] [PubMed]

18. Skibo, E.B.; Jamil, A.; Austin, B.; Hansen, D.; Ghodousi, A. Triple molecular target approach to selective melanoma cytotoxicity. Org. Biomol. Chem. 2010, 8, 1577-1587. [CrossRef]

19. Sharma, A.; Arambula, J.F.; Koo, S.; Kumar, R.; Singh, H.; Sessler, J.L.; Kim, J.S. Hypoxia-targeted drug delivery. Chem. Soc. Rev. 2019, 48, 771-813. [CrossRef] [PubMed]

20. Zhang, K.; Chen, D.; Ma, K.; Wu, X.; Hao, H.; Jiang, S. NAD(P)H:Quinone Oxidoreductase 1 (NQO1) as a therapeutic and diagnostic target in cancer. J. Med. Chem. 2018, 61, 6983-7003. [CrossRef]

21. Lynch, M.; Hehir, S.; Kavanagh, P.; Leech, D.; O'Shaughnessy, J.; Carty, M.P.; Aldabbagh, F. Synthesis by radical cyclization and cytotoxicity of highly potent bioreductive alicyclic ring fused [1,2-a] benzimidazolequinones. Chem. Eur. J. 2007, 13, 3218-3226. [CrossRef]

22. Hehir, S.; O’Donovan, L.; Carty, M.P.; Aldabbagh, F. Synthesis of dimethyl substituted benzimidazoles containing cyclopropane fused onto five to eight membered [1,2-a] alicyclic rings and influence of methyl group substituents on cytotoxicity of benzimidazolequinones. Tetrahedron 2008, 64, 4196-4203. [CrossRef]

23. Moriarty, E.; Carr, M.; Bonham, S.; Carty, M.P.; Aldabbagh, F. Synthesis and toxicity towards normal and cancer cell lines of benzimidazolequinones containing fused aromatic rings and 2-aromatic ring substituents. Eur. J. Med. Chem. 2010, 45, 3762-3769. [CrossRef]

24. Schulz, W.G.; Skibo, E.B. Inhibitors of topoisomerase II based on the benzodiimidazole and dipyrroloimidazobenzimidazole ring systems: Controlling DT-diaphorase reductive inactivation with steric bulk. J. Med. Chem. 2000, 43, 629-638. [CrossRef]

25. Suleman, A.; Skibo, E.B. A comprehensive study of the active site residues of DT-diaphorase: Rational design of benzimidazolediones as DT-diaphorase substrates. J. Med. Chem. 2002, 45, 1211-1220. [CrossRef]

26. Fagan, V.; Bonham, S.; Carty, M.P.; Aldabbagh, F. One-pot double intramolecular homolytic aromatic substitution routes to dialicyclic ring fused imidazobenzimidazolequinones and preliminary analysis of anticancer activity. Org. Biomol. Chem. 2010, 8, 3149-3156. [CrossRef] [PubMed]

27. Fagan, V.; Bonham, S.; McArdle, P.; Carty, M.P.; Aldabbagh, F. Synthesis and toxicity of new ring-fused imidazo[5,4f]benzimidazolequinones and mechanism using amine N-oxide cyclizations. Eur. J. Org. Chem. 2012, $2012,1967-1975$. [CrossRef] 
28. Fagan, V.; Bonham, S.; Carty, M.P.; Saenz-Méndez, P.; Eriksson, L.A.; Aldabbagh, F. COMPARE analysis of the toxicity of an iminoquinone derivative of the imidazo[5,4-f]benzimidazoles with NAD(P)H:quinone oxidoreductase 1 (NQO1) activity and computational docking of quinones as NQO1 substrates. Bioorg. Med. Chem. 2012, 20, 3223-3232. [CrossRef]

29. Conboy, D.; Aldabbagh, F. 6-Imino-1,2,3,4,8,9,10,11-octahydropyrido[1,2-a]pyrido[1' $\left., 2^{\prime}: 1,2\right]$ imidazo[4,5-f]benzimidazole-13-one: Synthesis and cytotoxicity evaluation. Molbank 2020, 2020, M118. [CrossRef]

30. Dawood, K.M.; Abdel-Wahab, B.F. Synthetic routes to benzimidazole-based fused polyheterocycles. ARKIVOC 2010, 333-389. [CrossRef]

31. Dawood, K.M.; Elwan, N.M.; Abdel-Wahab, B.F. Recent advances on the synthesis of azoles, azines and azepines fused to benzimidazole. ARKIVOC 2011, 111-195. [CrossRef]

32. Khajuria, R.; Rasheed, S.; Khajuria, C.; Kapoor, K.K.; Das, P. Recent developments in the synthesis of pyrido[1,2-a]benzimidazoles. Synthesis 2018, 50, 2131-2149. [CrossRef]

33. Manna, S.K.; Das, T.; Samanta, S. Polycyclic benzimidazole: Synthesis and photophysical properties. ChemistrySelect 2019, 4, 8781-8790. [CrossRef]

34. Spiegel, L.; Kaufmann, H. Reduction of dinitrophenylpiperidine. II. Communication. Ber. Dtsch. Chem. Ges. 1908, 41, 679-685. [CrossRef]

35. Bamberger, E.; Tschirner, F. Direct transformation of the aniline in phenylhydroxylamine. Ber. Dtsch. Chem. Ges. 1899, 32, 1675-1678. [CrossRef]

36. Nair, M.D.; Adams, R. Benzimidazole syntheses by oxidative cyclization with peroxytrifluoroacetic acid. J. Am. Chem. Soc. 1961, 83, 3518-3521. [CrossRef]

37. Meth-Cohn, O.; Suschitzky, H. Syntheses of heterocyclic compounds. Part IV. Oxidative cyclisation of aromatic amines and their $\mathrm{N}$-acyl derivatives. J. Chem. Soc. 1963, 4666-4669. [CrossRef]

38. Meth-Cohn, O. Mechanism of formation of benzimidazoles by oxidation of $o$-acylamino- $N, N$-dialkylanilines with peroxy-acids. $J$. Chem. Soc. C 1971, 1356-1357. [CrossRef]

39. Fahey, K.; Aldabbagh, F. Synthesis of seven- and eight-membered [1,2-a] alicyclic ring-fused benzimidazoles and 3aziridinylazepino[1,2-a]benzimidazolequinone as a potential antitumour agent. Tetrahedron Lett. 2008, 49, 5235-5237. [CrossRef]

40. Gurry, M.; McArdle, P.; Aldabbagh, F. Synthesis of a spirocyclic oxetane-fused benzimidazole. Molecules 2015, 20, 13864-13874. [CrossRef]

41. Hussain, H.; Green, I.R.; Ahmed, I. Journey describing applications of Oxone in synthetic chemistry. Chem. Rev. 2013, 113, 3329-3371. [CrossRef]

42. Alkhader, M.A.; Perera, R.C.; Sinha, R.P.; Smalley, R.K. Synthesis of polynuclear heterocycles. Part 4.1 imidazo[4,5- $g$ ] [3,1]benzoxazinones, imidazo[4,5-g]quinazolinones, imidazo[4,5-g]quinazolinediones, and imidazo[4,5-f]indazolinones. J. Chem. Soc. Perkin 1 1979, 1056-1062. [CrossRef]

43. Sweeney, M.; Gurry, M.; Keane, L.-A.J.; Aldabbagh, F. Greener synthesis using hydrogen peroxide in ethyl acetate of alicyclic ring-fused benzimidazoles and anti-tumour benzimidazolequinones. Tetrahedron Lett. 2017, 58, 3565-3567. [CrossRef]

44. Gernon, M.D.; Wu, M.; Buszta, T.; Janney, P. Environmental benefits of methanesulfonic acid. Comparative properties and advantages. Green Chem. 1999, 1, 127-140. [CrossRef]

45. Meth-Cohn, O.; Suschitzky, H.; Sutton, M.E. Oxidative cyclisations of $o$-substituted anilines and benzoic acids with manganese dioxide. J. Chem. Soc. C 1968, 1722-1726. [CrossRef]

46. Möhrle, H. Gerloff, Tricyclische benzimidazolderivate. J. Arch. Pharm. 1978, 311, 381-393. [CrossRef]

47. Sun, X.; Hu, Y.; Nie, S.-Z.; Yan, Y.-Y.; Zhang, X.-J.; Yan, M. Efficient construction of C=N double bonds via acceptorless dehydrogenative coupling. Adv. Synth. Catal. 2013, 355, 2179-2184. [CrossRef]

48. Sun, X.; Lv, X.-H.; Ye, L.-M.; Hu, Y.; Chen, Y.-Y.; Zhang, X.-J.; Yan, M. Synthesis of benzimidazoles via iridium-catalyzed acceptorless dehydrogenative coupling. Org. Biomol. Chem. 2015, 13, 7381-7383. [CrossRef]

49. Xue, D.; Long, Y.-Q. Metal-free TEMPO-promoted C $\left(\mathrm{sp}^{3}\right)-\mathrm{H}$ amination to afford multisubstituted benzimidazoles. J. Org. Chem. 2014, 79, 4727-4734. [CrossRef]

50. Thapa, P.; Palacios, P.M.; Tran, T.; Pierce, B.S.; Foss, F.W., Jr. 1,2-Disubstituted benzimidazoles by the iron catalyzed crossdehydrogenative coupling of isomeric o-phenylenediamine substrates. J. Org. Chem. 2020, 85, 1991-2009. [CrossRef]

51. Li, Q.-Y.; Cheng, S.-Y.; Tang, H.-T.; Pan, Y.-M. Synthesis of rutaecarpine alkaloids via an electrochemical cross dehydrogenation coupling reaction. Green Chem. 2019, 21, 5517-5520. [CrossRef]

52. Begunov, R.S.; Sakulina, V.O.; Syroeshkin, M.A.; Saverina, E.A.; Sokolov, A.A.; Minyaev, M.E. Electroreductive heterocyclization of ortho-piperidino substituted nitro(het)arenes. Mendeleev Commun. 2020, 30, 633-635. [CrossRef]

53. Martin, J.; Meth-Cohn, O.; Suschitzky, H. A simple route to polychlorobenzimidazoles and related systems. Tetrahedron Lett. 1973, 14, 4495-4498. [CrossRef]

54. Gurry, M.; Sweeney, M.; McArdle, P.; Aldabbagh, F. One-pot hydrogen peroxide and hydrohalic acid induced ring closure and selective aromatic halogenation to give new ring-fused benzimidazoles. Org. Lett. 2015, 17, 2856-2859. [CrossRef]

55. Sweeney, M.; Keane, L.-A.J.; Gurry, M.; McArdle, P.; Aldabbagh, F. One-pot synthesis of dihalogenated ring-fused benzimidazolequinones from 3,6-dimethoxy-2-(cycloamino)anilines using hydrogen peroxide and hydrohalic acid. Org. Lett. 2018, 20, 6970-6974. [CrossRef] 
56. Conboy, D.; Mirallai, S.I.; Craig, A.; McArdle, P.; Al-Kinani, A.A.; Barton, S.; Aldabbagh, F. Incorporating morpholine and oxetane into benzimidazolequinone antitumor agents: The discovery of 1,4,6,9-tetramethoxyphenazine from hydrogen peroxide and hydroiodic acid-mediated oxidative cyclizations. J. Org. Chem. 2019, 84, 9811-9818. [CrossRef]

57. Parr, R.G.; Szentpály, L.v.; Liu, S. Electrophilicity index. J. Am. Chem. Soc. 1999, 121, 1922-1924. [CrossRef]

58. Meth-Cohn, O.; Suschitzky, H. Heterocycles by ring closure of ortho-substituted $t$-anilines (The $t$-amino effect). Adv. Heterocycl. Chem. 1972, 14, 211-278. [CrossRef]

59. Kwast, A.; Stachowska, K.; Trawczyński, A.; Wróbel, Z. N-Aryl-2-nitrosoanilines as intermediates in the synthesis of substituted phenazines from nitroarenes. Tetrahedron Lett. 2011, 52, 6484-6488. [CrossRef]

60. Guttenberger, N.; Blankenfeldt, W.; Breinbauer, R. Recent developments in the isolation, biological function, biosynthesis, and synthesis of phenazine natural products. Bioorg. Med. Chem. 2017, 25, 6149-6166. [CrossRef] [PubMed]

61. Conboy, D.; Aldabbagh, F. The reactivity of Oxone towards 4,6-di(cycloamino)-1,3-phenylenediamines: Synthesis of spirocyclic oxetane ring-fused imidazobenzimidazoles. ARKIVOC 2020, 180-191. [CrossRef]

62. Purkait, A.; Roy, S.K.; Srivastava, H.K.; Jana, C.K. Metal-free sequential C( $\left.\mathrm{sp}^{2}\right)-\mathrm{H} / \mathrm{OH}$ and C( $\left.\mathrm{sp}^{3}\right)-\mathrm{H}$ aminations of nitrosoarenes and $N$-heterocycles to ring-fused imidazoles. Org. Lett. 2017, 19, 2540-2543. [CrossRef]

63. Saunders, K.H. Syntheses in the pyrido- and piperido-(1':2'-1:2)benzimidazole series. J. Chem. Soc. 1955, 3275-3287. [CrossRef]

64. Grantham, R.K.; Meth-Cohn, O. The formation of benzimidazolones and quinoxalines from o-nitrophenyldialkylanilines: A re-investigation. J. Chem. Soc. C 1969, 70-74. [CrossRef]

65. Skibo, E.B.; Islam, I.; Schulz, W.G.; Zhou, R.; Bess, L.; Boruah, R. The organic chemistry of the pyrrolo[1,2-a]benzimidazole antitumor agents. An example of rational drug design. Synlett 1996, 297-309. [CrossRef]

66. Suschitzky, H.; Sutton, M.E. Reductive cyclization of aromatic nitro compounds to benzimidazoles with titanous chloride. Tetrahedron 1968, 24, 4581-4587. [CrossRef]

67. Alonso, J.; Halland, N.; Nazaré, M.; R'kyek, O.; Urmann, M.; Lindenschmidt, A. A direct, regioselective palladium-catalyzed synthesis of $N$-substituted benzimidazoles and imidazopyridines. Eur. J. Org. Chem. 2011, 234-237. [CrossRef]

68. Hubbard, J.W.; Piegols, A.M.; Söderberg, B.C.G. Palladium-catalyzed N-heteroannulation of N-allyl- or N-benzyl-2nitrobenzenamines: Synthesis of 2-substituted benzimidazoles. Tetrahedron 2007, 63, 7077-7085. [CrossRef]

69. Joardar, S.; Bhattacharyya, A.; Das, S. A palladium on carbon catalyzed one-pot synthesis of substituted benzimidazoles. Synthesis 2014, 46, 3121-3132. [CrossRef]

70. Lu, C.; Su, Z.; Jing, D.; Jin, S.; Xie, L.; Li, L.; Zheng, K. Intramolecular reductive cyclization of $o$-nitroarenes via biradical recombination. Org. Lett. 2019, 21, 1438-1443. [CrossRef] [PubMed]

71. Nguyen, T.B.; Ermolenko, L.; Al-Mourabit, A. Redox condensation of $o$-halonitrobenzene with 1,2,3,4-tetrahydroisoquinoline: Involvement of an unexpected auto-catalyzed redox cascade. Chem. Commun. 2016, 52, 4914-4917. [CrossRef] [PubMed]

72. Nguyen, T.B.; Ermolenko, L.; Al-Mourabit, A. Formic acid as a sustainable and complementary reductant: An approach to fused benzimidazoles by molecular iodine-catalyzed reductive redox cyclization of o-nitro-t-anilines. Green Chem. 2016, 18, 2966-2970. [CrossRef]

73. Deng, X.; McAllister, H.; Mani, N.S. CuI-catalyzed amination of arylhalides with guanidines or amidines: A facile synthesis of 1H-2-substituted benzimidazoles. J. Org. Chem. 2009, 74, 5742-5745. [CrossRef]

74. Liubchak, K.; Nazarenko, K.; Tolmachev, A. Synthesis of annulated benzimidazoles via amidine cyclization. Tetrahedron 2012, 68, 2993-3000. [CrossRef]

75. Baars, H.; Beyer, A.; Kohlhepp, S.V.; Bolm, C. Transition-metal-free synthesis of benzimidazoles mediated by KOH/DMSO. Org. Lett. 2014, 16, 536-539. [CrossRef] [PubMed]

76. Chen, Y.; Xu, F.; Sun, Z. Synthesis of 1,2-disubstituted benzimidazoles using an aza-Wittig-equivalent process. RSC Adv. 2017, 7, 44421-44425. [CrossRef]

77. Geng, X.; Liu, S.; Wang, W.; Qu, J.; Wang, B. tert-Amino effect-promoted rearrangement of aryl isothiocyanate: A versatile approach to benzimidazothiazepines and benzimidazothioethers. J. Org. Chem. 2020, 85, 12635-12643. [CrossRef]

78. Huang, J.; He, Y.; Wang, Y.; Zhu, Q. Synthesis of benzimidazoles by PIDA-promoted direct C(sp $\left.{ }^{2}\right)$-H imidation of $N$-arylamidines. Chem. Eur. J. 2012, 18, 13964-13967. [CrossRef] [PubMed]

79. Kutsumura, N.; Kunimatsu, S.; Kagawa, K.; Otani, T.; Saito, T. Synthesis of benzimidazole-fused heterocycles by intramolecular oxidative C-N bond formation using hypervalent iodine reagents. Synthesis 2011, 3235-3240. [CrossRef]

80. Rasheed, S.; Rao, D.N.; Das, P. Copper-catalyzed inter- and intramolecular C-N bond formation: Synthesis of benzimidazolefused heterocycles. J. Org. Chem. 2015, 80, 9321-9327. [CrossRef]

81. Elder, M.S.; Melson, G.A.; Busch, D.I. Reactions of coordinated ligands. XII. The synthesis of $o$-benzylene-2,1-benzimidazole in the presence of nickel(II) ions, and a study of some of its metal complexes. Inorg. Chem. 1966, 5, 74-77. [CrossRef]

82. Chen, J.; Qu, J.; Zhang, Y.; Chen, Y.; Liu, N.; Chen, B. Metal-free construction of tricyclic or tetracyclic compounds, acidpromoted synthesis of benzo[4,5]imidazo[2,1-a]isoindole and 1,2-dialkyl-2,3-dihydrobenzimidazoles. Tetrahedron 2013, 69, 316-319. [CrossRef]

83. Anastasiou, D.; Campi, E.M.; Chaouk, H.; Jackson, W.R. Synthesis of benzimidazoles containing a fused alicyclic ring by rhodium-catalysed hydroformylation of $N$-alkenyl-1,2-diaminobenzenes. Tetrahedron 1992, 48, 7467-7478. [CrossRef]

84. De Selms, R.C. Benzimidazoles. II. Synthesis of $N$-heterocyclic ring systems containing 1,2-fused benzimidazole moieties. J. Org. Chem. 1962, 27, 2165-2167. [CrossRef] 
85. Haque, M.R.; Rasmussen, M. Ambident heterocyclic reactivity: Intramolecular alkylations of 2,4-disubstituted benzimidazoles. Tetrahedron 1997, 53, 6937-6958. [CrossRef]

86. Qin, H.; Miao, Y.; Xu, J.; Bi, Q.; Qu, W.; Liu, W.; Feng, F.; Sun, H. A facile and efficient [4 + 2] annulation reaction of sulfur ylides: Access to $N$-fused benzimidazoles. Org. Chem. Front. 2019, 6, 205-208. [CrossRef]

87. Almansour, A.I.; Arumugam, N.; Kumar, R.S.; Soliman, S.M.; Altaf, M.; Ghabbour, H.A. Synthesis, spectroscopic, X-ray diffraction and DFT studies of novel benzimidazole fused-1,4-oxazepines. Molecules 2016, 23, 724. [CrossRef] [PubMed]

88. Zhao, G.; Chen, C.; Yue, Y.; Yu, Y.; Peng, J. Palladium(II)-catalyzed sequential C-H arylation/aerobic oxidative C-H amination: One-pot synthesis of benzimidazole-fused phenanthridines from 2-arylbenzimidazoles and aryl halides. J. Org. Chem. 2015, 80, 2827-2834. [CrossRef] [PubMed]

89. Tan, K.L.; Vasudevan, A.; Bergman, R.G.; Ellman, J.A.; Souers, A.J. Microwave-assisted C-H bond activation: A rapid entry into functionalized heterocycles. Org. Lett. 2003, 5, 2131-2134. [CrossRef]

90. Wang, Y.-X.; Qi, S.-L.; Luan, Y.-X.; Han, X.-W.; Wang, S.; Chen, H.; Ye, M. Enantioselective Ni-Al bimetallic catalyzed exo-selective C-H cyclization of imidazoles with alkenes. J. Am. Chem. Soc. 2018, 140, 5360-5364. [CrossRef]

91. Loup, J.; Müller, V.; Ghorai, D.; Ackermann, L. Enantioselective aluminum-free alkene hydroarylations through C-H activation by a chiral nickel/JoSPOphos manifold. Angew. Chem. Int. Ed. 2019, 58, 1749-1753. [CrossRef]

92. Zhang, X.; Zhou, Y.; Wang, H.; Guo, D.; Ye, D.; Xu, Y.; Jiang, H.; Liu, H. Silver-catalyzed intramolecular hydroamination of alkynes in aqueous media: Efficient and regioselective synthesis for fused benzimidazoles. Green Chem. 2011, 13, 397-405. [CrossRef]

93. Dhole, S.; Sun, C.-M. Direct access to dihydrobenzoimidazo[2,1-a]isoquinolines through ruthenium-catalyzed formal [4+2] annulation. Adv. Synth. Catal. 2019, 361, 535-541. [CrossRef]

94. Pereira, K.C.; Porter, A.L.; DeBoef, B. Intramolecular arylation of benzimidazoles via Pd(II)/Cu(I) catalyzed cross-dehydrogenative coupling. Tetrahedron Lett. 2014, 55, 1729-1732. [CrossRef] [PubMed]

95. Guo, X.; Hu, J.; Zhang, M.; Wang, L. Palladium-catalyzed C( $\left.\mathrm{sp}^{2}\right)$-H activation for the formation of C-N bonds: Rapid access to benzimidazoquinazolines. Asian J. Org. Chem. 2019, 8, 417-421. [CrossRef]

96. Xu, H.; Zhang, Y.; Huang, J.; Chen, W. Copper-catalyzed synthesis of N-fused heterocycles through regioselective 1,2aminothiolation of 1,1-dibromoalkenes. Org. Lett. 2010, 12, 3704-3707. [CrossRef] [PubMed]

97. Kwak, J.P.; Dao, P.D.Q.; Cho, C.S. Synthesis of 2-aminoquinazoline- and 2-aminopyrimidine-fused hybrid scaffolds by coppercatalyzed $\mathrm{C}\left(\mathrm{sp}^{2}\right)-\mathrm{N}$ coupling and cyclization followed by oxidation. Eur. J. Org. Chem. 2020, 2020, 3468-3474. [CrossRef]

98. Diep, T.D.; Dao, P.D.Q.; Ho, S.L.; Cho, C.S. Copper-catalyzed synthesis of trinuclear N-fused hybrid scaffolds by double C(sp2)-N bond formation between 2-(2-bromoaryl)indoles and 2-aminoazoles. Eur. J. Org. Chem. 2020, 2020, 2807-2812. [CrossRef]

99. Lopes, A.B.; Wagner, P.; Gulea, M. Synthesis of benzimidazole-fused medium-sized N,S-heterocycles via palladium-catalyzed cyclizations. Eur. J. Org. Chem. 2019, 1361-1370. [CrossRef]

100. Joyce, E.; McArdle, P.; Aldabbagh, F. Acetic anhydride generated imidazolium ylide in ring closures onto carboxylic acids; part of the synthesis of new potential bioreductive antitumor agents. Synlett 2011, 1097-1100. [CrossRef]

101. Joyce, E.; Kavanagh, P.; Leech, D.; Karpinska, J.; McArdle, P.; Aldabbagh, F. Acetic anhydride mediated condensation of aromatic $o$-diacid dichlorides with benzimidazoles to provide electro-reducible $p$-dione adducts. Tetrahedron Lett. 2012, 53, 3788-3791. [CrossRef]

102. O'Connell, J.M.; Moriarty, E.; Aldabbagh, F. Access to aromatic ring-fused benzimidazoles using photochemical substitutions of the benzimidazol-2-yl radical. Synthesis 2012, 44, 3371-3377. [CrossRef]

103. Clyne, M.A.; Aldabbagh, F. Photochemical intramolecular aromatic substitutions of the imidazol-2-yl radical are superior to those mediated by $\mathrm{Bu}_{3} \mathrm{SnH}$. Org. Biomol. Chem. 2006, 4, 268-277. [CrossRef]

104. Coyle, R.; Fahey, K.; Aldabbagh, F. Barton esters for initiator-free radical cyclisation with heteroaromatic substitution. Org. Biomol. Chem. 2013, 11, 1672-1682. [CrossRef]

105. Moriarty, E.; Aldabbagh, F. Synthesis of aryl ring-fused benzimidazolequinones using 6-exo-trig radical cyclizations. Tetrahedron Lett. 2009, 50, 5251-5253. [CrossRef]

106. McLoughlin, P.T.F.; Clyne, M.; Aldabbagh, F. Intermolecular "oxidative" aromatic substitution reactions of the imidazol-5-yl radical mediated by the "reductant" Bu 3 SnH. Tetrahedron 2004, 60, 8065-8071. [CrossRef]

107. Beckwith, A.L.J.; Bowry, V.W.; Bowman, W.R.; Mann, E.; Parr, J.; Storey, J.M.D. The mechanism of Bu 3 SnH-mediated homolytic aromatic substitution. Angew. Chem. Int. Ed. 2004, 43, 95-98. [CrossRef] [PubMed]

108. Gurry, M.; Aldabbagh, F. A new era for homolytic aromatic substitution: Replacing $\mathrm{Bu}_{3} \mathrm{SnH}$ with efficient light-induced chain reactions. Org. Biomol. Chem. 2016, 11, 3849-3862. [CrossRef]

109. Coyle, R.; McArdle, P.; Aldabbagh, F. Tandem reactions via Barton esters with intermolecular addition and vinyl radical substitution onto Indole. J. Org. Chem. 2014, 79, 5903-5907. [CrossRef] [PubMed]

110. Pan, C.; Yuan, C.; Yu, J.-T. Peroxide-mediated synthesis of benzimidazo[2,1-a]isoquinoline-6(5H)-ones via cascade methylation/ethylation and intramolecular cyclization. Org. Biomol. Chem. 2021, 19, 619-626. [CrossRef]

111. Sun, K.; Li, S.-J.; Chen, X.L.; Liu, Y.; Huang, X.-Q.; Wei, D.-H.; Qu, L.-B.; Zhao, Y.-F.; Yu, B. Silver-catalyzed decarboxylative radical cascade cyclization toward benzimidazo[2,1-a]isoquinolin-6(5H)-ones. Chem. Commun. 2019, 55, 2861-2864. [CrossRef]

112. Bera, S.K.; Alam, M.T.; Mal, P. C-N coupling via antiaromatic endocyclic nitrenium ions. J. Org. Chem. 2019, 84, 12009-12020. [CrossRef] [PubMed] 
113. Dao, P.D.Q.; Cho, C.S. Construction of binuclear benzimidazole-fused quinazolinones and pyrimidinones using aryl isocyanates as building blocks by transition-metal-free $\mathrm{C}\left(\mathrm{sp}^{2}\right)-\mathrm{N}$ coupling. J. Org. Chem. 2020, 85, 13354-13362. [CrossRef]

114. Chen, W.; Du, Y.; Wang, M.; Fang, Y.; Yu, W.; Chang, J. Synthesis of benzo[4,5]imidazo[1,2-a]quinoxalines by $\mathrm{I}_{2}-\mathrm{mediated}^{3} \mathrm{sp}^{3} \mathrm{C}-\mathrm{H}$ amination. Org. Chem. Front. 2020, 7, 3705-3708. [CrossRef]

115. O'Shaughnessy, J.; Cunningham, D.; Kavanagh, P.; Leech, D.; McArdle, P.; Aldabbagh, F. Synthesis of benzimidazolequinone analogue of cyclopropamitosene antitumor agents. Synlett 2004, 2382-2384. [CrossRef]

116. O'Shaughnessy, J.; Aldabbagh, F. Synthesis of pyrrolo- and pyrido[1,2-a]benzimidazolequinone anti-tumor agents containing a fused cyclopropane ring. Synthesis 2005, 1069-1076. [CrossRef]

117. Aldabbagh, F.; Bowman, W.R. Radical cyclisation onto imidazoles and benzimidazoles. Tetrahedron 1999, 55, 4109-4122. [CrossRef]

118. Conboy, D.; Kielty, P.; Bear, J.C.; Cockcroft, J.K.; Farras, P.; McArdle, P.; Singer, R.J.; Smith, D.A.; Aldabbagh, F. Ring-fused dimethoxybenzimidazole-benzimidazolequinone (DMBBQ): Tunable halogenation and quinone formation using NaX/Oxone. Org. Biomol. Chem. 2021, 19, 2716-2724. [CrossRef] [PubMed] 